\title{
Simulating transient ice-ocean Ekman transport in the Regional Arctic System Model and Community Earth System Model
}

\author{
Andrew ROBERTS, ${ }^{1}$ Anthony CRAIG, ${ }^{1}$ Wieslaw MASLOWSKI, ${ }^{1}$ Robert OSINSKI, ${ }^{2}$ \\ Alice DuVIVIER, ${ }^{3}$ Mimi HUGHES, ${ }^{3}$ Bart NIJSSEN, ${ }^{4}$ John CASSANO, ${ }^{3}$ \\ Michael BRUNKE ${ }^{5}$ \\ ${ }^{1}$ Naval Postgraduate School, Monterey, CA, USA \\ E-mail: afrobert@nps.edu \\ ${ }^{2}$ Polish Institute of Oceanology, Sopot, Poland \\ ${ }^{3}$ University of Colorado, Boulder, CO, USA \\ ${ }^{4}$ University of Washington, Seattle, WA, USA \\ ${ }^{5}$ University of Arizona, Tucson, AZ, USA
}

\begin{abstract}
This work evaluates the fidelity of the polar marine Ekman layer in the Regional Arctic System Model (RASM) and Community Earth System Model (CESM) using sea-ice inertial oscillations as a proxy for ice-ocean Ekman transport. A case study is presented that demonstrates that RASM replicates inertial oscillations in close agreement with motion derived using the GPS. This result is obtained from a year-long case study pre-dating the recent decline in perennial Arctic sea ice, using RASM with sub-hourly coupling between the atmosphere, sea-ice and ocean components. To place this work in context, the RASM coupling method is applied to CESM, increasing the frequency of oceanic flux exchange from once per day in the standard CESM configuration, to every $30 \mathrm{~min}$. For a single year simulation, this change causes a considerable increase in the median inertial ice speed across large areas of the Southern Ocean and parts of the Arctic sea-ice zone. The result suggests that processes associated with the passage of storms over sea ice (e.g. oceanic mixing, sea-ice deformation and surface energy exchange) are underestimated in Earth System Models that do not resolve inertial frequencies in their marine coupling cycle.
\end{abstract}

KEYWORDS: atmosphere/ice/ocean interactions, climate change, polar and subpolar oceans, sea-ice dynamics, sea-ice modelling

\section{INTRODUCTION}

Amid many efforts to better simulate 21 st-century Arctic seaice decline, there is a growing impetus within the scientific community to resolve modeled polar oceanic and atmospheric physics that are contingent upon high spatial resolution land-atmosphere $(\leq 50 \mathrm{~km})$ and ice-ocean $\left(\leq 1 / 10^{\circ}\right)$ models (Maslowski and others, 2012). Many Earth System Models cited in the latest Intergovernmental Panel on Climate Change (IPCC) Assessment Report (Stocker and others, 2013) do not resolve these scales and are therefore unable to simulate mesoscale Arctic storms, high-latitude oceanic eddies, narrow Arctic boundary currents, oceanic tides or linear kinematic features in sea ice. These are only a few examples from a long list of polar processes and physics contingent upon high spatial resolution, the importance of which remains to be fully investigated for their impact on simulated polar climate. Notwithstanding, evidence from stand-alone atmosphere and ice-ocean models, as well as observations, indicates that such processes increase local sub-daily variance within the polar environment, with expected energy cascades to climatic timescales (e.g. Holloway and Proshutinsky, 2007; Maslowski and others, 2008; DuVivier and Cassano, 2013). Coupled processes that are primarily contingent upon high temporal resolution have often received less attention in Earth System Models, and in this paper we focus on one such physical interaction in the polar oceans: inertial oscillations in sea ice, which may be considered a proxy for transient Ekman transport in the ice-ocean boundary layer (Heil and Hibler, 2002; Hibler and others, 2006).

There is a dearth of literature on the simulation of iceocean inertial oscillations in fully coupled Earth System Models, partly because they are difficult to evaluate in global climate models using only short buoy records. Simulating them requires frequent ( hourly) atmosphere-ice-ocean flux exchange, which can be computationally restrictive. For example, the Community Earth System Model (CESM; Hurrell and others, 2013) exchanges time-averaged oceanic fluxes at daily intervals (following Gent and others, 2011), which naturally filters semi-diurnal feedbacks between ice, ocean and the atmosphere, removing the oscillatory Ekman transport signal from interfacial ice-ocean stress. By contrast, some of the best sea-ice simulations in the recent Coupled Model Intercomparison Project (CMIP5) were from the ACCESS model (Stocker and others, 2013) which includes ice-ocean flux exchange at hourly or half-hourly intervals (Bi and others, 2013). A direct result of less frequent coupling is that ice-ocean Ekman transport is damped, even though the sea-ice and ocean models may represent inertial oscillations internally. In this paper, we aim to demonstrate the importance of frequent atmosphere-ice-ocean coupling in simulating polar Ekman transport using two fully coupled models. We evaluate established sea-ice and ocean codes in a fully coupled regional climate model against observations of inertial oscillations in sea ice. We then apply guidance from this work in a new CESM configuration to assess the effect of 

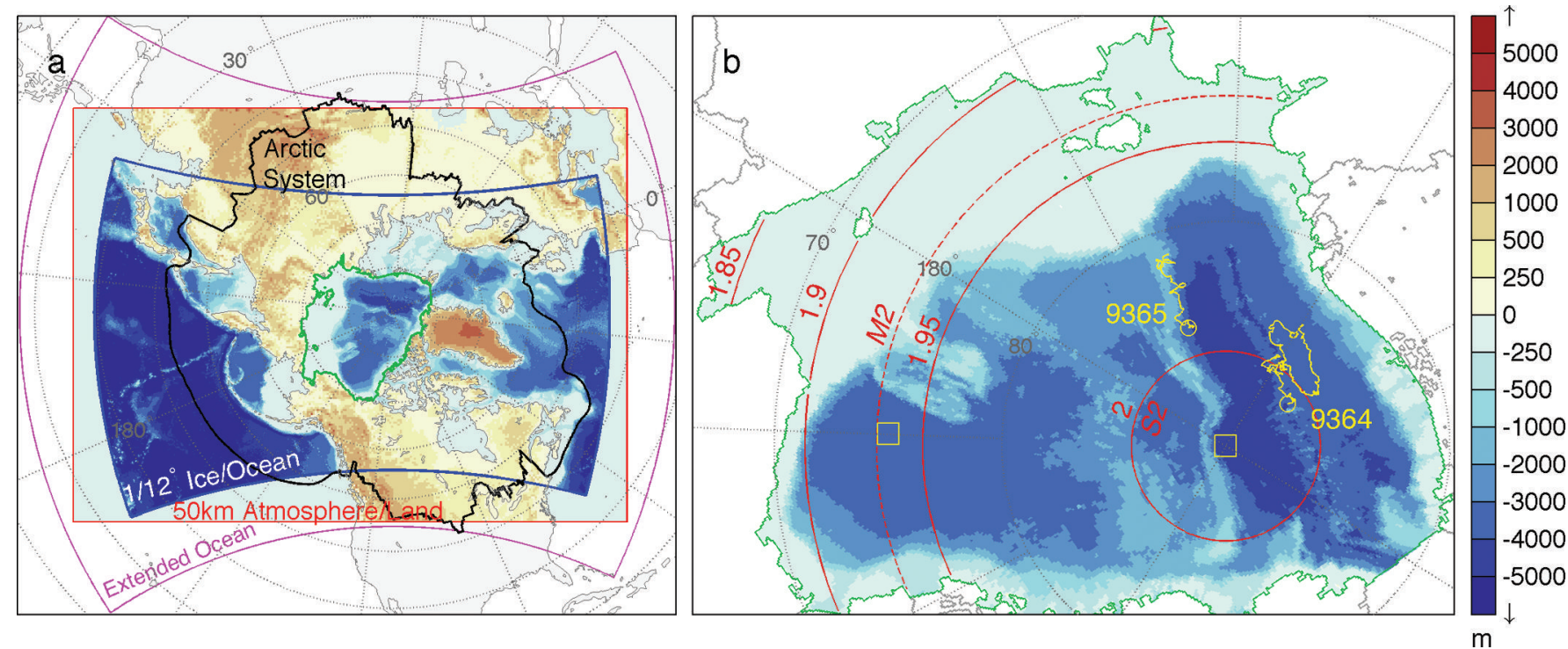

Fig. 1. Configuration of the Regional Arctic System Model and the central Arctic analysis region used in this study. (a) Boundaries of the iceocean domain (blue outline and resolved bathymetry), the atmosphere-land domain boundary (red) and the extended ocean domain (magenta). Topographic and bathymetric pixels (shading) represent single model gridcells on the $50 \mathrm{~km}$ atmosphere-land and $\sim 9 \mathrm{~km}$ iceocean domains, respectively. The Arctic System boundary indicates the area north of the 1990-99 mean $10^{\circ} \mathrm{C}$ sea surface and surface air $0^{\circ} \mathrm{C}$ isotherms that encircle the North Pole, and the southern limit of terrain that drains into the High Arctic as defined in Roberts and others (2010). The area encircled by the green line represents the central analysis domain used for the RASM case study in this paper, which is enlarged in (b). (b) The yellow buoy tracks and end-point circles indicate the track of IABP drifters 9364 and 9365 for the year 1996 as used by Heil and Hibler (2002). Yellow boxes show the location of time-series analysis for the Community Earth System Model in Figure 11. Red contours indicate the inertial frequency $\left(\mathrm{d}^{-1}\right)$, and the latitudes at which M2 and S2 tidal oscillations share the inertial frequency.

high-frequency coupling on simulated transient ice-ocean Ekman transport in the Arctic and Southern Ocean. To place this work in context, it is useful to first review prominent modeling and observational analysis that has heretofore advanced our understanding of this topic.

\section{TRANSIENT ICE-OCEAN EKMAN TRANSPORT}

Following McPhee (1978), Heil and Hibler (2002) and Hibler and others (2006), and neglecting advective acceleration, evolution of the combined, idealized ice-ocean Ekman transport, $\widetilde{M}$, may be described as

$$
\frac{\partial \widetilde{M}}{\partial t}=\widetilde{\tau}_{a}-f \mathbf{k} \times \widetilde{M}+\nabla \cdot \sigma_{m n}
$$

where $\widetilde{\tau}_{a}$ is the surface wind stress vector, $f$ is the Coriolis parameter, $\mathbf{k}$ is the unit vector normal to the sea surface and $\sigma_{m n}$ is the internal sea-ice stress tensor $(m, n=1,2)$ resulting from sea-ice velocity in the absence of geostrophic flow for time $t$. Neglecting snow accumulated on the surface of sea ice, the combined ice-ocean Ekman transport can be expressed as the sum of ice and ocean components:

$$
\widetilde{M}=\rho_{\mathrm{i}} h_{\mathrm{i}} \widetilde{u}_{\mathrm{ie}}+\int_{-\infty}^{0} \rho_{\mathrm{o}} \widetilde{u}_{\mathrm{oe}}(z) \mathrm{d} z
$$

where $\rho$ is density, $\widetilde{u}_{\mathrm{e}}$ is the Ekman component of the boundary layer ice-ocean velocity, $h_{\mathrm{i}}$ is sea-ice thickness, $z$ is ocean depth, and subscripts $i$ and o denote sea ice and ocean, respectively. Equation (1) describes a forced harmonic oscillator damped by internal ice stress, which is dependent upon sea-ice concentration and thickness. As they decrease, $\nabla \cdot \sigma_{m n}$ declines nonlinearly (e.g. Thorndike and others, 1975; Hibler, 1980; Bitz and others, 2001). When internal ice stress is negligible, Eqn (1) reduces to a second-order inhomogeneous partial differential equation, for which the analytic solution demonstrates that $\widetilde{M}$ traces a clockwise perfect local circle with a period $T=2 \pi / f$ ranging from approximately 11.96 to 17 hours in the Northern Hemisphere sea-ice zone, and 12.21 to 14.60 hours in the Southern Hemisphere sea-ice zone. By virtue of Eqn (2), the Ekman component of sea-ice velocity, $\widetilde{u}_{i e}$, rotates in phase with and has a magnitude proportional to $\widetilde{M}$, and may therefore be measured as a proxy for ice-ocean Ekman transport and used as an indicator of stress-induced mixing in the ice-ocean boundary layer.

Inertial oscillations have been measured in Arctic and Southern Ocean sea ice using a variety of techniques. They are typically excited by impulsive wind forcing or internal ice stress (e.g. Hunkins, 1967; Hibler and others, 1998; Kwok and others, 2003; Geiger and Perovich, 2008; McPhee, 2008; Leppäranta and others, 2012), especially during the passage of storms over polar oceans (e.g. Lammert and others, 2009). However, up until the routine use of GPS locations in the International Arctic Buoy Program (IABP) from $\sim 2005$ onwards, the extent to which inertial oscillations affect basin-scale sea-ice deformation, growth and melt was unclear. However, evidence is emerging of climatic changes in inertial oscillations in sea ice attributable to mechanical weakening of the pack (Gimbert and others, 2012a). Inertial oscillations in sea ice interfere with tidal waves in polar oceans at certain latitudes (e.g. Fig. 1), and provide a source of ocean surface stress for the generation of near-inertial waves that disperse downward and horizontally in the ocean (e.g. Guthrie and others, 2013). This has important implications for our understanding of the seasonality of oceanic mixing in polar oceans.

Global and hemispheric studies of the contribution of inertia to oceanic mixing have heretofore neglected polar 
areas (e.g. Park and others, 2005, 2009) or do not explicitly address complications relating to sea-ice cover (e.g. Rath and others, 2014), partly because of a lack of observations. However, some measurements of enhanced oceanic mixing resulting from Ekman pumping induced by sea-ice mechanics or from a reduced ice cover exist for the Beaufort Sea (e.g. Rainville and Woodgate, 2009; Dosser and others, 2014). A number of modeling studies have investigated the impact of inertial oscillations on sea-ice drift and deformation in the Arctic, including McPhee (1978), Heil and Hibler (2002) and Hibler and others (2006). Related work to 'embed' sea ice in baroclinic ocean models has helped to improve the barotropic mode of which Ekman transport is a component (e.g. Campin and others, 2008; Griffies, 2010). Much of the analysis of so called 'high-frequency ice-ocean dynamics' in models has been confined to stand-alone iceocean simulations and there are few studies addressing the relevant physics in fully coupled climate models. Previous stand-alone ice-ocean Arctic modeling studies have typically used 6 hourly interpolated wind forcing from reanalyses, which causes unavoidable complications: The driving wind stress contains an alias at the Nyquist frequency $\left(\nu=2 \mathrm{~d}^{-1}\right)$, artificially exciting the Ekman layer in a latitudinal band surrounding $85^{\circ} \mathrm{N} \approx \sin ^{-1}(v \pi / \Omega)$, given Earth's angular frequency of rotation $\Omega=6.3042 \mathrm{rad} \mathrm{d}^{-1}$. Direct linear forcing of the Ekman layer north of this latitude is neglected, including a considerable tract of the Transpolar Drift. Use of an anti-alias filter to avert the aliasing only expands the region around the North Pole without linear forcing at the resonant frequency of the system, due to loss of wind stress power near and at the Nyquist frequency. As a result it has been difficult to assess the relative basin-wide contribution of nonlinear sea-ice mechanics and direct linear wind forcing of the ice-ocean boundary layer prior to the availability of 3 hourly reanalysis data. Use of 3 hourly reanalysis fields averts this problem but still neglects highfrequency feedbacks with the atmosphere (e.g. Gimbert and others, 2012a), preventing a full assessment of the contribution of Ekman transport to variance within the atmosphere-ice-ocean boundary layer system.

In this paper, we present an inertial oscillation case study based on results from a fully coupled model that allows coupled feedbacks not present in stand-alone ice-ocean simulations, and also facilitates validation methods not possible in global models. The Regional Arctic System Model (RASM) used in this study is a fully coupled highresolution climate model that comprehensively resolves the ice-ocean inertial period. Because RASM is fully coupled, it negates the aforementioned problems of aliasing and lowpass filtration of surface fluxes. In previous research in stand-alone ice-ocean models, high-frequency Arctic Ocean dynamics have addressed diurnal tidal interaction as well as inertial oscillations (e.g. Hibler and others, 2006; Chen and others, 2009), but here we limit our fully coupled model analysis to the latter and confine our study prior to the onset of the rapid decline of perennial Arctic sea-ice volume in the past decade. The aim of our investigation is to isolate the ice-ocean Ekman transport signal in a single RASM realization and gain an understanding of its simulated basin-wide seasonal progression. Because RASM is regionally constrained, it facilitates model evaluation using daily observations for a specific year in the climate record. This is prohibitive in global coupled models because global internal variability restricts the minimum time window over
Table 1. Spatial and temporal resolution of the Regional Arctic System Model as used in this study

\begin{tabular}{|c|c|c|}
\hline Component & Code & Configuration \\
\hline Atmosphere & WRF3 & $50 \mathrm{~km}, 40$ levels, $2.5 \mathrm{~min}$ time step \\
\hline Land & VIC & $50 \mathrm{~km}, 3$ soil layers, $20 \mathrm{~min}$ time step \\
\hline Ocean & POP2 & $\begin{array}{l}\left.1 / 12^{\circ}, 45 \text { levels ( } 7 \text { in the top } 42 \mathrm{~m}\right), 10 \text { time } \\
\text { steps per } 20 \mathrm{~min} \text { flux exchange }\end{array}$ \\
\hline Sea ice & CICE4 & $\begin{array}{c}1 / 12^{\circ}, 5 \text { thickness categories divided at } 0.65 \\
1.39,2.47,4.56,9.3 \mathrm{~m} \\
4 \text { thermodynamic ice layers per category and } \\
1 \text { snow layer } \\
20 \text { min thermodynamics and } 2 \text { min dynamics } \\
\text { time step }\end{array}$ \\
\hline Coupler & CPL7x & Flux exchange every $20 \mathrm{~min}$ for all components \\
\hline
\end{tabular}

which Earth System Models can be compared with observations, depending on ensemble size. But here we can use RASM as a fully coupled framework to evaluate ice-ocean Ekman transport. We then apply to CESM the methods evaluated in RASM to demonstrate how changes in iceocean coupling affect Ekman transport in one prominent global model cited in the latest IPCC (Stocker and others, 2013) report.

\section{THE REGIONAL ARCTIC SYSTEM MODEL}

RASM is a limited-area, fully coupled atmosphere-iceocean-land model consisting of the Weather Research and Forecasting (WRF) model, Los Alamos National Laboratory (LANL) Parallel Ocean Program (POP) and Sea Ice Model (CICE) and the Variable Infiltration Capacity (VIC) land hydrology model. RASM is configured on the pan-Arctic domain displayed in Figure $1 \mathrm{a}$, and covers the entire Northern Hemisphere marine cryosphere, terrestrial drainage to the Arctic Ocean, major inflow and outflow pathways, with extension into the North Pacific and Atlantic oceans to account for the passage of cyclones into the Arctic. WRF and VIC share a $50 \mathrm{~km}$ resolution polar stereographic mesh, and POP and CICE share a $1 / 12^{\circ}$ rotated sphere grid with the equator passing through the North Pole. This provides a horizontal ice-ocean resolution of $\sim 9 \mathrm{~km}$ across the Arctic Ocean, which is eddy-permitting across the entire domain. An extended ocean domain surrounds the boundaries of the POP/CICE mesh to pass observed surface boundary conditions to WRF where the atmospheric mesh extends beyond the ocean model's lateral boundaries, similar to the method used by Dorn and others (2007). A major advantage of this RASM configuration is that there are no native poles on any of the model grids, avoiding significant grid convergence that can arbitrarily filter waves in high-latitude simulations. Table 1 summarizes the discretization within each component model.

RASM in this study uses the same sea-ice and ocean models (CICE and POP) as CESM Version 1.1. Most relevant to this research is the sea-ice dynamics configuration, which uses the elastic-viscous-plastic (EVP) rheology as first described by Hunke and Dukowicz (1997) and subsequently updated, as summarized in Hunke and Lipscomb (2010). RASM uses five sea-ice thickness categories to represent compressive sea-ice strength as indicated in Table 1, assuming isostasy following Rothrock (1975) but 

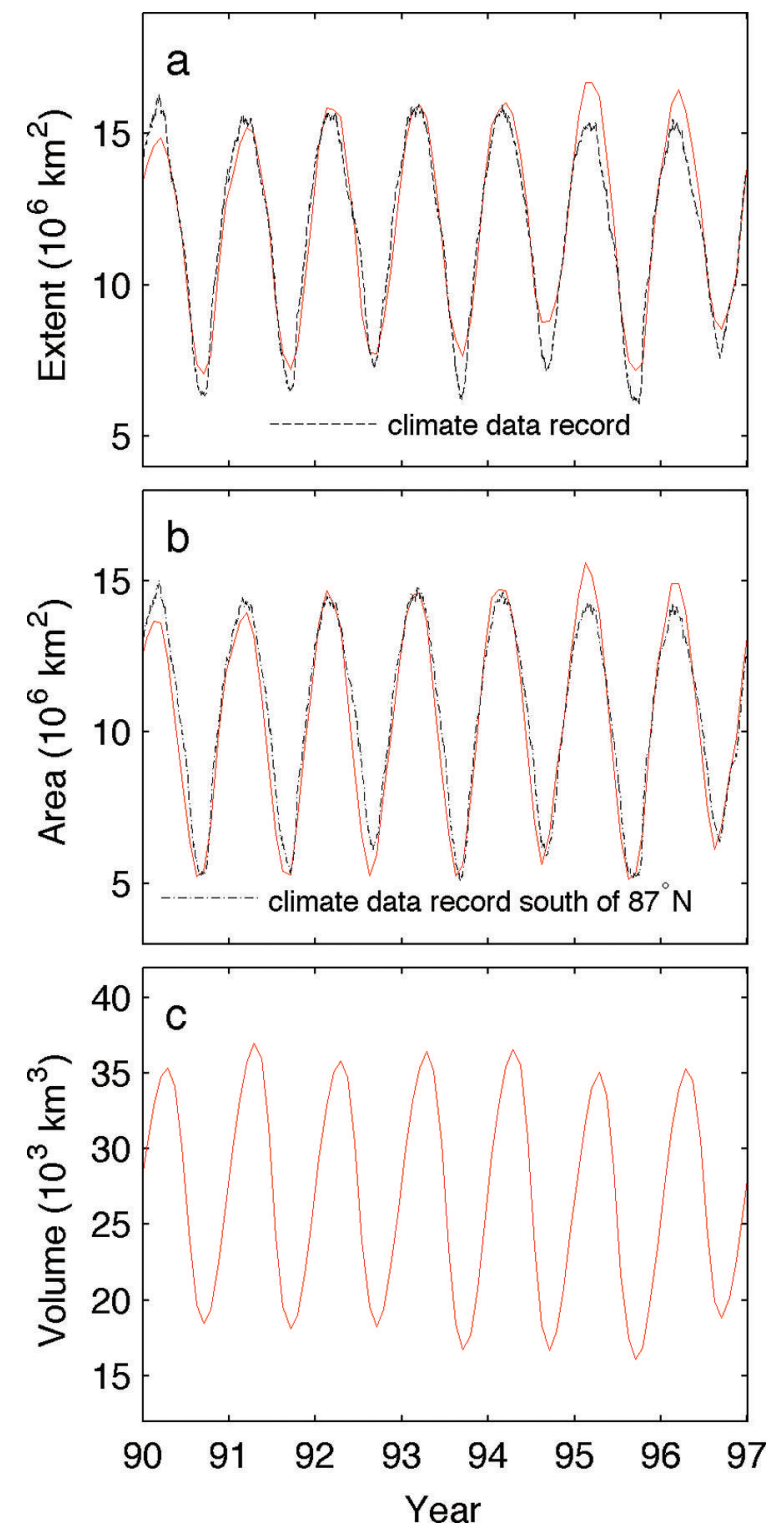

Fig. 2. Model-observation comparison of sea-ice (a) extent, (b) area and (c) thickness, for RASMe1 (red). Extent is limited to ice categories $>0.3 \mathrm{~m}$ thick for comparison against the passive microwave climate data record. The ice area comparison avoids the gap in Special Sensor Microwave/Imager (SSM/I) retrievals surrounding the North Pole.

with an exponential ridged ice thickness distribution (Lipscomb and others, 2007) and 94\% of kinetic energy lost to friction during ridge building. A variable atmospheric drag coefficient is calculated over sea ice following Brunke and others (2006), in combination with a constant iceocean drag coefficient of $C_{\mathrm{o}}=0.00536$. Further details of this coupling are provided in Appendix A, which describes how the Polar Science Center Hydrographic Climatology (PHC) is used for prescribed oceanic boundary conditions.

Coupling of all RASM components is based on the same flux coupler as CESM Version 1.1, denoted as CPL7 (Craig and others, 2012). However, for this study, CPL7 has undergone significant modifications especially relevant to high-frequency sea-ice motion. In particular, we have modified the coupling sequence to ensure there is no more than one coupling time-step lag between the sea-ice and ocean models. Coupled models inherently possess lags, which can cause instabilities if these lags become too great relative to the period of the signals within the coupled system. Therefore it is important to model ice-ocean Ekman transport so that the lag between $\widetilde{u}_{\text {ie }}$ and $\widetilde{u}_{\text {oe }}$ in Eqn (2) is as small as possible. Our new version of CPL7, which we denote CPL7x, ensures this is the case when using the standard RASM 20 min coupler step. This satisfies idealized Kuramoto stability criteria (e.g. Mirollo and Strogatz, 2005) for two coupled oscillators pulsing at the same inertial frequency within sea-ice zones. It also satisfies the Hallberg (2014) stability equations for ice-ocean models. The $20 \mathrm{~min}$ coupling in RASM ensures a coupling phase lag of $\sim 10^{\circ}$ or less between $\widetilde{u}_{\mathrm{ie}}$ and $\widetilde{u}_{\mathrm{oe}}$, and $\sim 15^{\circ}$ or less for the $30 \mathrm{~min}$ high-frequency CESM coupling used in this paper.

Details on the atmosphere and land model configurations in RASM may also be found in Appendix A. Most important to this work is that we spectrally nudge WRF to ERA-Interim reanalyses (Dee and others, 2011) above $500 \mathrm{hPa}$ up to wavenumbers 4 and 3 on the abscissa and ordinate axes, respectively, of the WRF domain (Fig. 1a). The limits of wavenumber nudging are proportional to the relative lengths of the axes. We nudge the temperature and wind with a strength of 0.0003 (see Skamarock and others, 2008, for information about the precise physical meaning of this parameter). This configuration allows the atmosphere-iceocean boundary layer system to freely evolve under the constraint of large-scale upper atmospheric circulation, including the polar vortex, consistent with the 6 hourly ERA-Interim lateral boundary conditions used in this study.

\section{ICE-OCEAN EKMAN TRANSPORT IN THE REGIONAL ARCTIC SYSTEM MODEL}

Regional coupled models provide a platform for detailed model evaluation against daily measurements while including coupled atmospheric feedbacks. Using RASM as a fully coupled climate evaluation platform, we focus here on its ability to simulate inertial oscillations in sea ice and compare the results with daily observations. We have confined our RASM case study to 1996 and our analysis to the central Arctic region shown in Figure 1b. The case-study year pre-dates the 21 st-century rapid decline of summer Arctic sea-ice extent, and can be compared with previously published modeling results on Arctic inertial oscillations by Heil and Hibler (2002). We initialized our RASM simulation, herein referred to as RASMe1, on 1 September 1989 and ran the model to the end of 1996. The land and iceocean components are initialized with spun-up states from their respective stand-alone versions forced respectively with ERA-Interim and CORE-2 reanalyses (Large and Yeager, 2008). WRF was initialized with ERA-Interim at the start of September 1989.

To evaluate the domain-wide performance of RASMe1, we use a passive microwave climate data record (CDR) of sea-ice extent and area as described by Meier (2013). In comparing with the CDR, we have filtered for sea ice less than $0.3 \mathrm{~m}$ in the thinnest model category, reflecting the likely underestimation of ice concentration in the marginal ice zone when measured using passive microwave techniques (e.g. Karvonen, 2014). The model overestimates seaice extent in light of this uncertainty (Fig. 2), but this is of little consequence for the central Arctic analysis region.

We also evaluated the surface geostrophic wind field against 3 monthly ERA-Interim averages. The model surface 

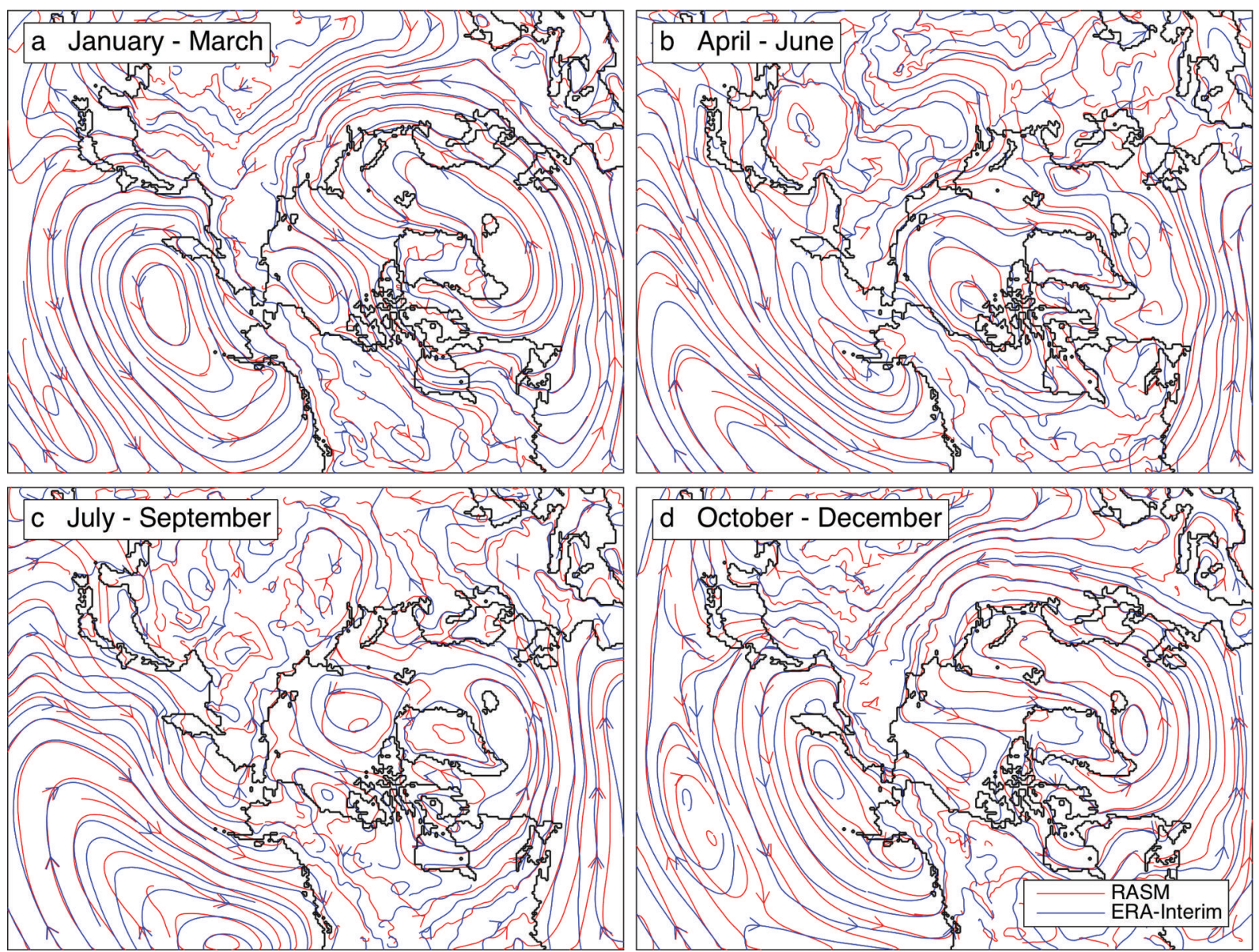

Fig. 3. Mean seasonal surface geostrophic wind on the RASM atmospheric model domain, indicating low wind-forcing bias over sea ice. Red streamlines represent the RASMe1 surface flow for 1992-96, and blue streamlines represent the corresponding ERA-Interim circulation. Successive 3 month averages (a-d) correspond to the same time periods in Figure $4 a-d$. The black coastal boundary indicates the division along which the $1 / 12^{\circ} \mathrm{POP} / \mathrm{CICE}$ grid projects a surface type of $50 \%$ land and $50 \%$ sea ice or ocean onto the lower-resolution $50 \mathrm{~km}$ WRF mesh.

atmospheric circulation does not possess any substantial semi-decadal bias relative to ERA-Interim reanalyses (Fig. 3). As a result, we are able to isolate discrepancies in simulated sea-ice drift (Fig. 4) to factors other than surface wind field bias, something that is not readily possible in fully coupled global simulations. Increased cyclonic activity over the pack between July and September (Fig. 3) reflects in a disruption of the Beaufort Gyre and Transpolar Drift during summer (Fig. 4). During July-September, a mean cyclonic wind circulation pattern develops that is centered over the North Pole, corresponding to a greater number of low-pressure systems traversing the central Arctic in summer.

Given these broad model statistics, RASM sea-ice velocity is evaluated against 3 hourly sea-ice drift derived from GPS locations of two 1996 IABP drifters in the Amundsen Basin. These Alfred Wegener Institute buoys, denoted IABP 9364 and 9365 (Fig. 1b), provide some of the best Arctic GPS surface drift records pre-dating 2000. Data from the same two buoys were used by Heil and Hibler (2002), and have been processed identically in this study as in theirs. The IABP 9364 drift record used in this study spans all of 1996, while IABP 9365 begins on 23 August 1996 and is used for the remainder of that year. During 1996, both of these buoys were located close to the latitude at which the S2 tide imposes a weak, anticlockwise rotation and a weaker clockwise rotation at the inertial frequency (Fig. 1b) congruent with its Beaufort Sea amphidromic point as demonstrated by Kowalik and Proshutinsky (1994), Hibler and others (2006), Chen and others (2009) and Pnyushkov and Polyakov (2012).

A useful way to compare ice-ocean Ekman transport between buoys and models is with rotary spectral analysis (Appendix B). This method enables clockwise and anticlockwise sea-ice motion to be separated and placed into frequency bands, so that the semi-diurnal clockwise (anticlockwise) rotation of $\widetilde{u}_{\text {ie }}$ in the Northern (Southern) Hemisphere can be evaluated separately from longer periods and counter-rotational sea-ice drift. Using this method, RASM simulates inertial oscillations in sea-ice drift that are statistically comparable with observed oscillations (Fig. 5).

The rotary power spectral density (Fig. 5a) exhibits similar magnitudes for the model and buoys including secondary peaks at $-2 \mathrm{~d}^{-1}$, which indicates close agreement between the observations and model for the annual mean inertial motion in sea ice at that location. This result by itself demonstrates the ability of RASM to simulate transient Ekman transport that is comparable to the real world. Perhaps the largest observation-model difference (Fig. 5) can be seen in the $+2 \mathrm{~d}^{-1}$ peaks, which are most likely due to tides. As mentioned, IABP 9364 and 9365 are located close to the S2 tidal interference latitude (Fig. 1b) so that tides and inertia cannot be differentiated based solely on the frequency modulus of spectral peaks. Even so, using rotary spectra with signed frequency, there is a trade-off between frequency 

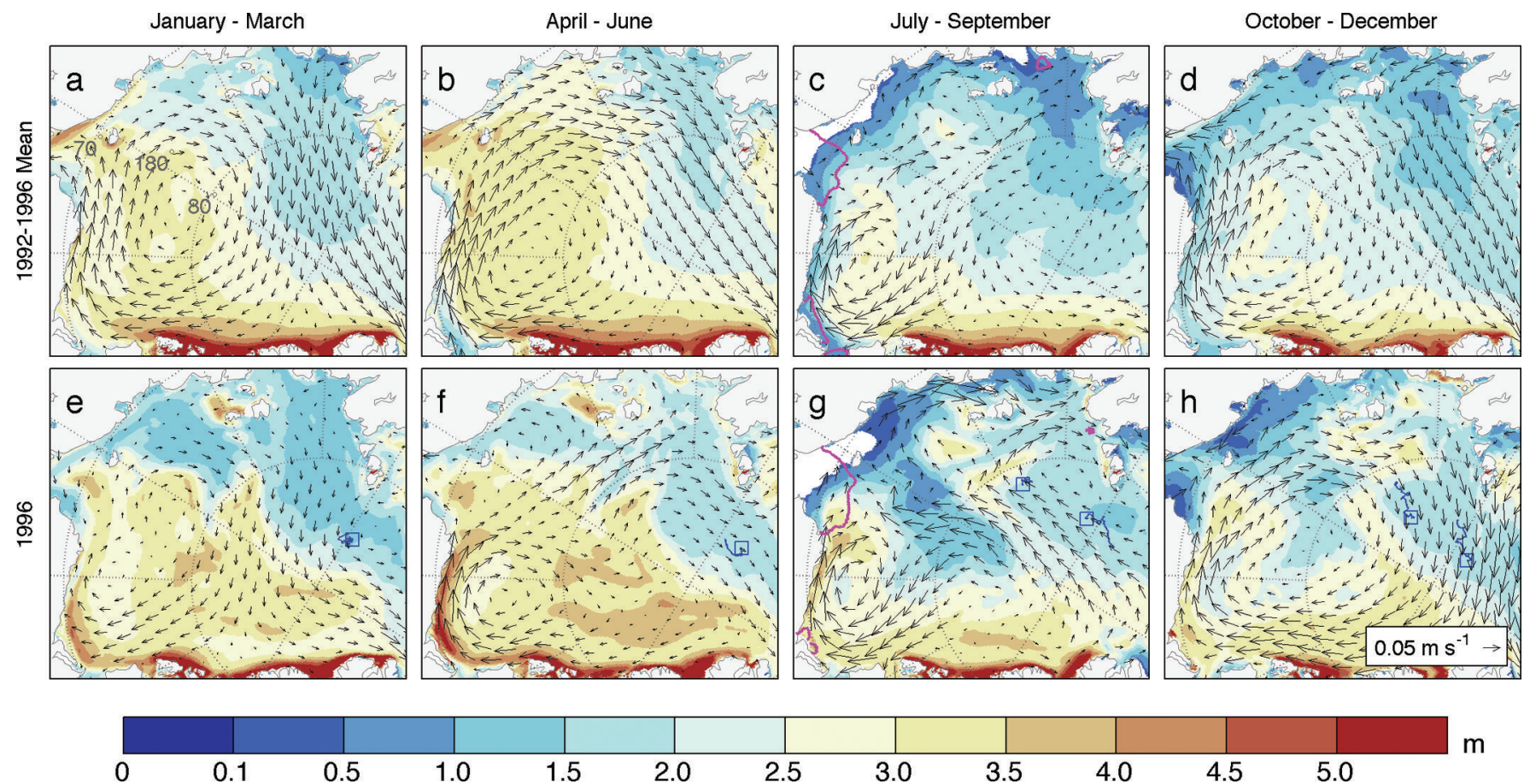

Fig. 4. Mean central Arctic sea-ice thickness (shading) and drift (vectors) for RASMe1 during 1992-96 (a-d) and 1996 only (e-h) wherever model concentration exceeds $15 \%$. Each vector represents a mean of 256 model gridcell velocities, masked for land. The comparable climate data record sea-ice extent is shown in magenta. Navy-blue traces indicate the seasonal drift track of IABP buoys 9364 and 9365 as indicated in Figure $1 \mathrm{~b}$ and corresponding to their respective times of operation. Boxes are positioned on the end buoy position for the 1996 3 month windows indicated for each frame.

resolution $\left(0.0623 \mathrm{~d}^{-1}\right.$; Fig. 5) and statistical significance. Consequently, north of $78.8^{\circ} \mathrm{N}$ one cannot distinguish S2 tidal peaks from inertial peaks solely on the frequency modulus. However, the frequency sign (rotation sense) does provide evidence of inertial oscillations of greater magnitude than tidal waves. This is because the small observed semidiurnal anticlockwise peaks in power spectral density (Fig. 5; blue lines, $+2 \mathrm{~d}^{-1}$ ) are suggestive of the S2 tidal signal, in accordance with Kowalik and Proshutinsky (1994) and
Pnyushkov and Polyakov (2012). Their work suggests that the dominant $\mathrm{S} 2$ and $\mathrm{M} 2$ tidal signals are anticlockwise in the vicinity of IABP 9365. In other words, the dominant tidal signal (anticlockwise) rotates in the opposite direction to the dominant inertial signal (clockwise).

There is a further complication in analyzing sea-ice dynamics using rotary spectra, in that this technique gives no indication of how inertial oscillations manifest when internal stress $\left(\nabla \cdot \sigma_{m n}\right)$ is not negligible in Eqn (1). Geiger
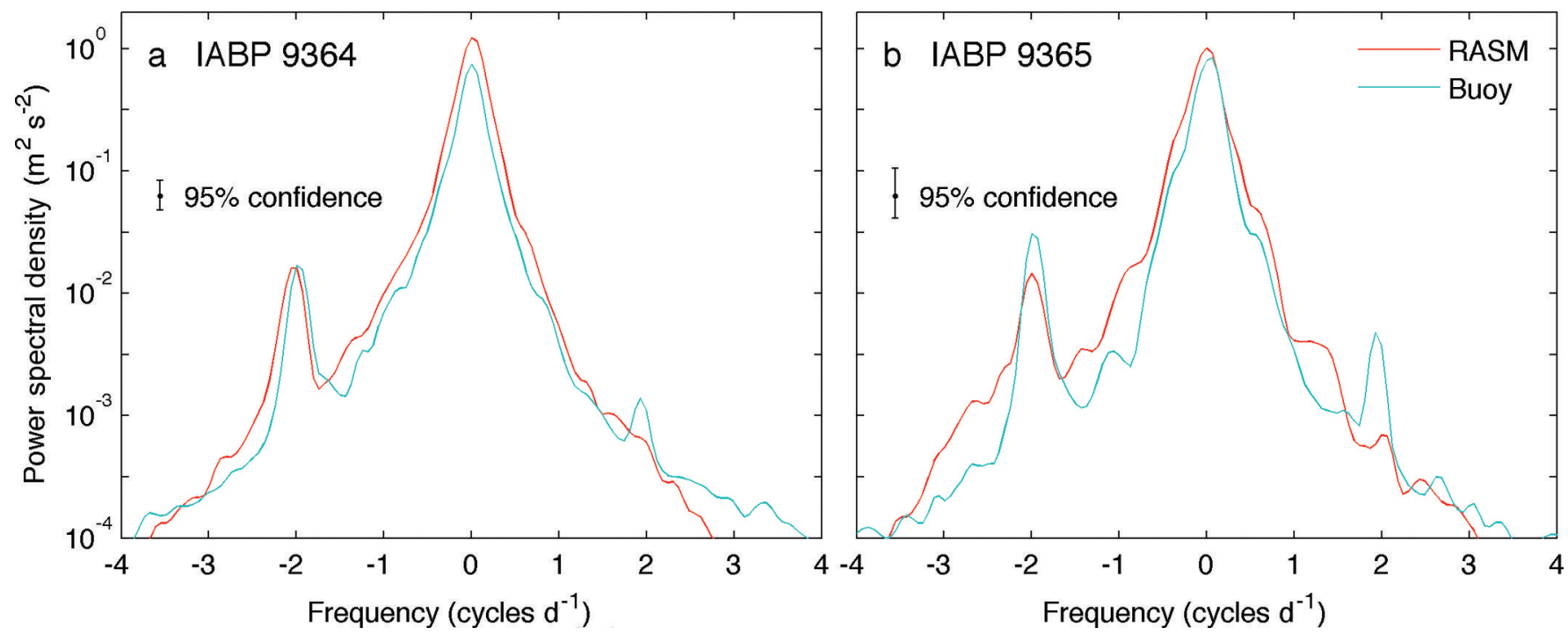

Fig. 5. Rotary power spectral density for observed drift (blue) calculated from IABP buoys 9364 and 9365 located in Figures 1 and 4 , with corresponding spectra for RASMe1 (red). Negative (positive) frequencies indicate clockwise (anticlockwise) motion. The IABP 9364 spectrum in (a) represents all of 1996, while the IABP 9365 spectrum in (b) represents 23 August to 30 December 1996, and consequently has lower confidence bounds. 

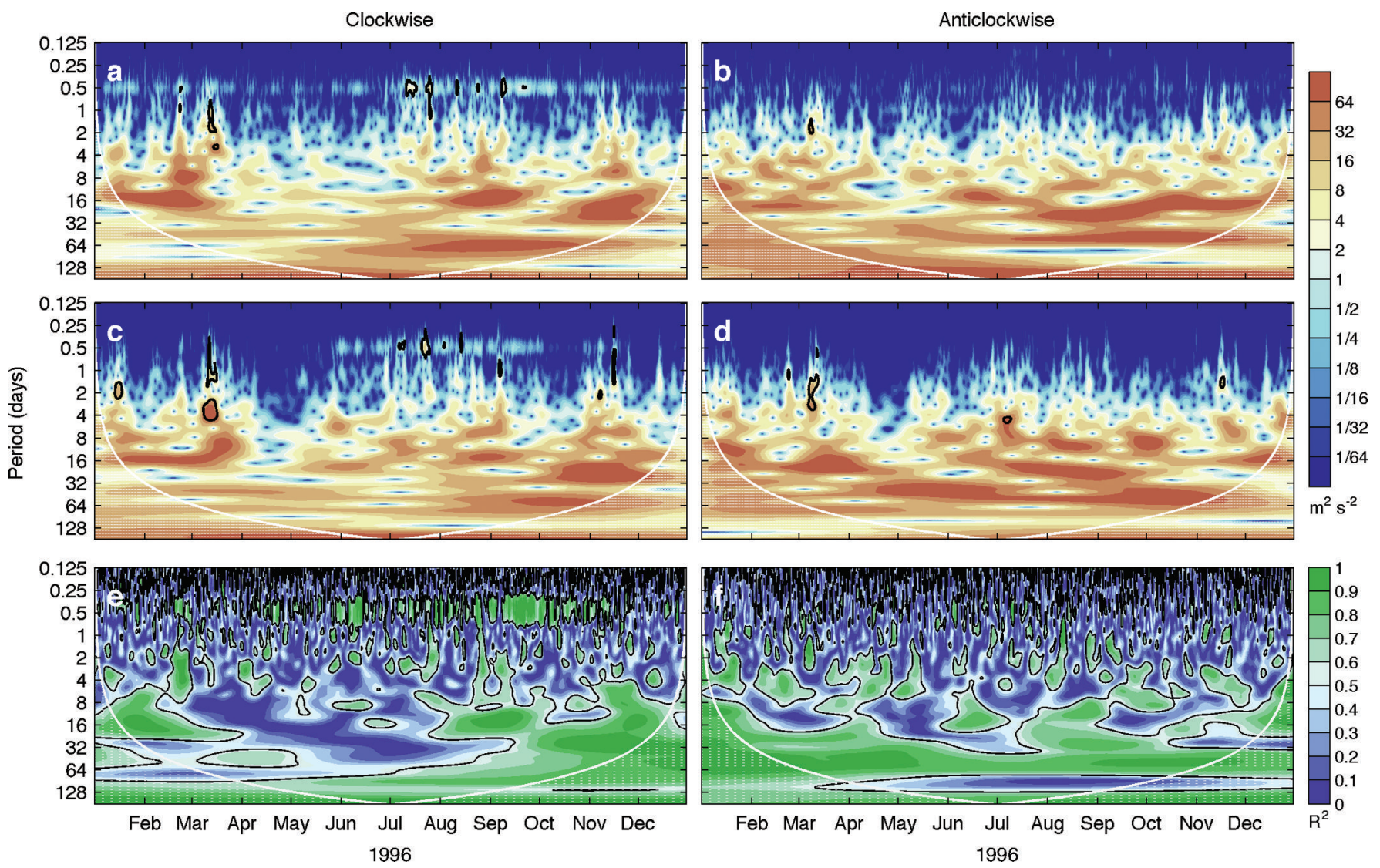

Fig. 6. Observed (a) clockwise and (b) anticlockwise rotary wavelet power of sea-ice drift for IABP buoy 9364, and the corresponding modeled (c) clockwise and (d) anticlockwise rotary wavelet power corresponding to spectra in Figure 5a. The modeled and observed wavelet cross-coherence squared statistic $\left(R^{2}\right)$ is shown for (e) clockwise and (f) anticlockwise motion. Black contours indicate 95\% confidence against red noise, and white hatching indicates the cone of influence subject to edge effects. Time series used to construct this figure are summarized in Figure 7.

and Perovich (2008) provide specific measurements of inertial oscillations west of the Antarctic Peninsula, and demonstrate that sea ice does not always trace recognizable inertial loops along the drift track in compact ice. Instead, the sea ice may drift along a straighter path, and accelerate or decelerate at the inertial frequency along that path. In rotary spectra, this behavior manifests as both clockwise and anticlockwise inertial peaks, in the same way that a tidal ellipse manifests as clockwise and anticlockwise spectral peaks (see Emery and Thomson, 2004, for details). Therefore, it cannot be presumed from our analysis so far that $\sim+2 \mathrm{~d}^{-1}$ anticlockwise peaks solely indicate $\mathrm{M} 2$ and S2 tidal motion free from interference by inertial oscillations.

We apply rotary wavelet analysis, which can isolate signals by their period at a point in time (Liu and Miller, 1996). Rotary wavelet analysis has previously been used to identify physical causes and their timing in ocean currents (e.g. Hormazabal and others, 2004), and we use it here to isolate tidal and inertial signals in sea-ice drift (see Appendix B). It is an ideal tool to differentiate between forcing from ever-present tidal constituents, and forcing from sea-ice inertial oscillations that are excited by intermittent storms. This is because individual storm events can be depicted from constant tidal forcing in rotary-filtered time series, something that rotary spectra do not allow. We have constructed time-evolving wavelet rotary spectral power of sea-ice drift (Fig. 6). The wavelet spectra reveal a rich record of clockwise and anticlockwise drift, which enables the identification of synoptic storm activity passing over the IABP 9364 location in the real world and in the model. For the weaker semi-diurnal signal of interest in this study, the dominant observed signal is clearly inertial, not tidal, as indicated by the strong semi-diurnal power in the clockwise mode (Fig. 6a) versus less semi-diurnal power in the anticlockwise mode (Fig. 6b). The tidal component will necessarily have stronger anticlockwise rotation relative to the clockwise direction, which is the converse of what can be seen here.

A further advantage of rotary wavelet analysis is that it provides a measure of the relative agreement of both power and periodicity of two signals at a specific point in time. This is achieved via the wavelet coherence squared statistic $\left(R^{2}\right)$, which can be thought of as a frequency space analogue to correlation in time. However, the most important property of the $R^{2}$ statistic is that relatively small differences between time series can result in poor coherence squared values. This is further explained in Appendix $B$, but the key point here is that statistically significant $R^{2}$ values exceeding 0.9 indicate very close agreement between a model and observations, in this case for sea-ice drift magnitude at a given frequency and rotation sense. There is strong coherence of ice motion between RASMe1 and IABP 9364 near or at the clockwise half-day period during summer, when inertial oscillations were most pronounced (Fig. 6e). However, for the remainder of the year, there is less agreement except in the case of rare, statistically significant inertial oscillation events. A similar result exists in the wavelet comparison of IABP 9365 with RASMe1 (not 

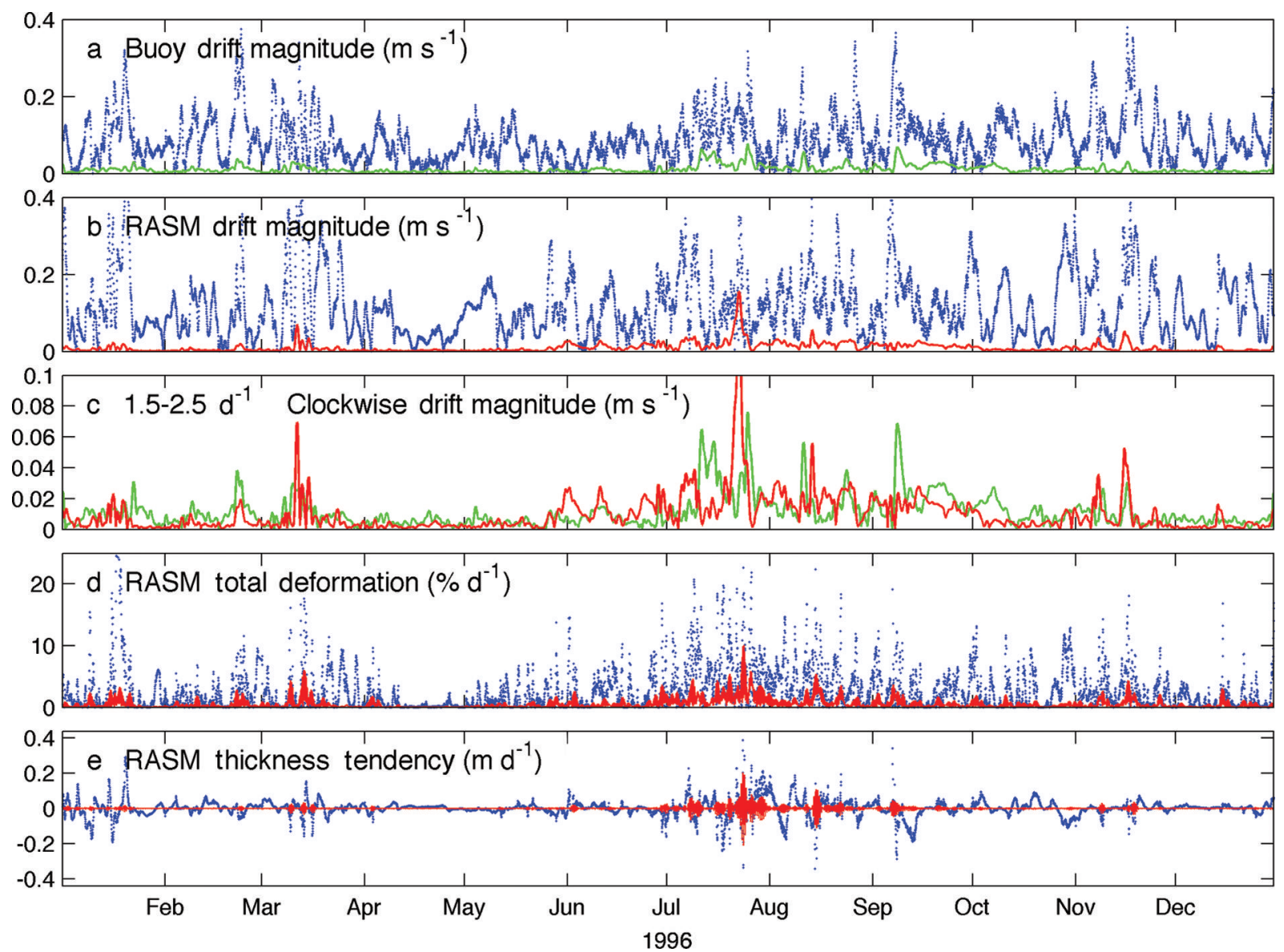

Fig. 7. (a) IABP 9364 sea-ice drift speed and (b) corresponding RASMe1 drift for the complete time series (blue) and $1.5-2.5 \mathrm{~d}^{-1}$ clockwise drift magnitude, also shown in (c) for direct comparison between the observed (green) and modeled (red) results on a smaller scale. The co-located RASMe1 (d) total deformation and (e) combined dynamic and thermodynamic thickness change indicate the $1.5-2.5 \mathrm{~d}^{-1}$ signal (red) as against the unfiltered hourly time series (blue).

shown). However, that comparison is less straightforward because IABP 9365 was deployed after much of the 1996 summer had passed.

The corresponding time series illustrate the observed (Fig. 7a) and modeled (Fig. 7b) broadband (all-frequency) drift corresponding to IABP 9364. The corresponding inertial drift magnitude is isolated using a clockwise $1.5-2.5 \mathrm{~d}^{-1}$ rotary filter, shown in green for IABP 9364 (Fig. 7a), and in red for the collocated RASMe1 time series (Fig. 7b). Methods used to prepare Figure 7 are described in Appendix B. When interpreting the direct comparison between inertial oscillation magnitude in the model and that of buoy IABP 9364 (Fig. 7c), it is important to take into account that RASM is fully coupled. Therefore the precise timing and strength of inertial oscillations will rarely line up exactly, because RASM is subject to internal variability in the same way as global fully coupled models are, except here this variability is only regional. Still, in some cases the timing of modeled and observed extreme events closely matches, especially where weather systems passing over the ice are driven by longwave atmospheric circulation, to which RASM is closely constrained by boundary conditions.

One should expect similar seasonality and non-stationary high-frequency sea-ice drift in the model to that in the observations, which we submit is the case when assessing Figures 5-7 together. The key outcome of these results is that overall RASMe1 and IABP 9364 inertial sea-ice drift speeds are comparable within the bounds of differences stemming from seasonal variability. This is also evident in the close agreement between the major peaks in modeled and observed rotary spectral drift (Fig. 5, within the -1.5 to $+1.5 \mathrm{~d}^{-1}$ frequency range). Although inertial oscillations typically constitute a small fraction of total speed in both the modeled and buoy drift (Fig. 7), they contribute more substantially to total deformation and thickness in RASM. This can be seen by comparing the red trace with the blue time series in Figure $7 d$ and e where total deformation is $\sqrt{\text { divergence }^{2}+\text { shear }^{2}}$, and thickness tendency includes both dynamics and thermodynamics. It is evident that for the most part, inertial oscillations contribute background noise to the sea-ice drift solution, interspersed with non-stationary pulses significant in the complete deformation signal. These pulses predominantly occur during summer.

\section{SEASONALITY AND SPATIAL DISTRIBUTION OF INERTIAL OSCILLATIONS IN RASME1 DURING 1996}

While high-frequency drift and deformation is statistically dominated by small values, there are comparatively rare yet extreme inertial oscillations and associated sea-ice fracture in the modeled and observed drift records presented in the previous section. Such extreme events are evident at the $2 \mathrm{~d}^{-1}$ wavelet power (Fig. 7). To further analyze these statistical characteristics in the model, we filtered clockwise 

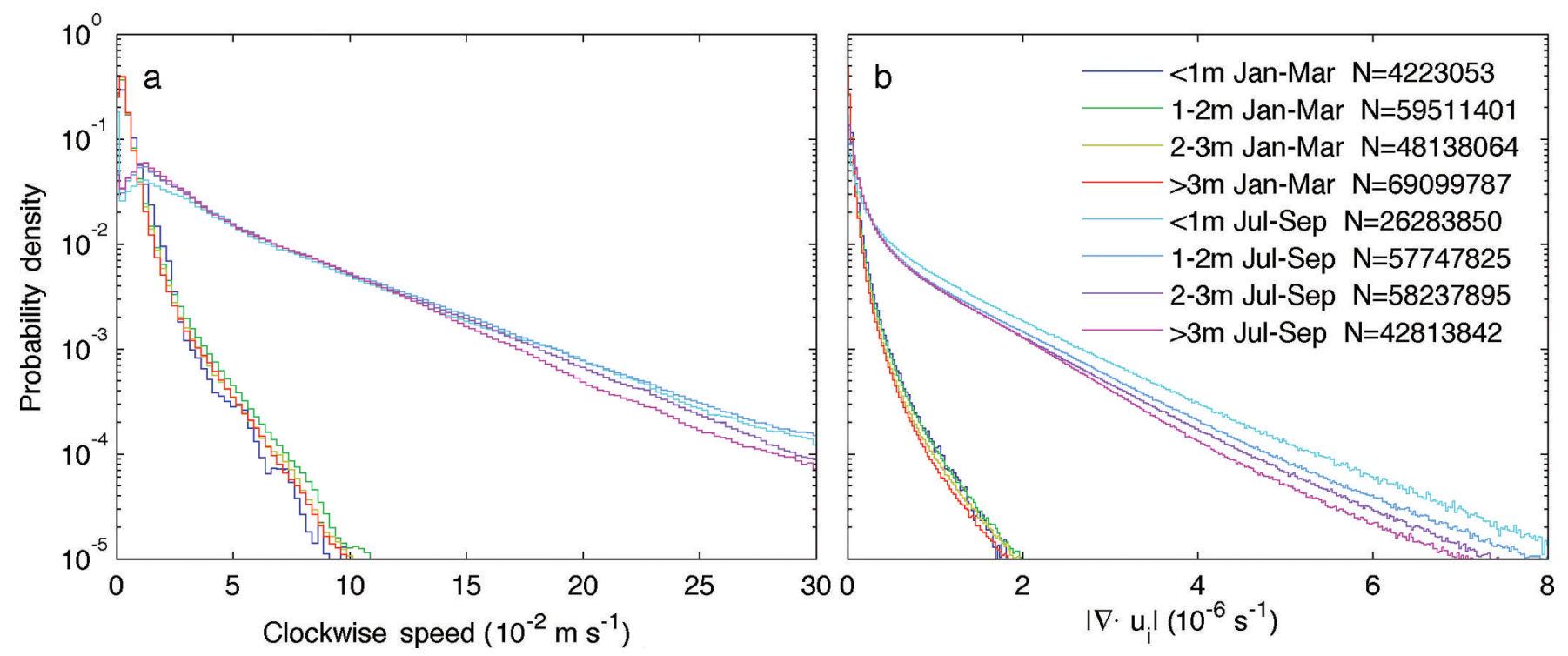

Fig. 8. RASMe1 normalized probability density of (a) 1.8-2.1 $\mathrm{d}^{-1}$ clockwise inertial drift and (b) corresponding divergence magnitude for model gridcells in the central Arctic analysis region. Individual histograms are filtered to include only the mean gridcell thickness and 3 month period as denoted in the legend (January-March and July-September). Hourly samples with sea-ice concentration $<15 \%$ are excluded. $N$ indicates the total number of hourly samples used to construct each histogram after applying the mask, using $2.5 \times 10^{-3} \mathrm{~m} \mathrm{~s}^{-1}$ and $2.5 \times 10^{-8} \mathrm{~m} \mathrm{~s}^{-1}$ bin sizes for drift and deformation, respectively.

1.8-2.1 $\mathrm{d}^{-1}$ drift and deformation from hourly RASMe1 output. These filtered data were then used to construct probability density curves for January-March and JulySeptember 1996 over the Arctic Ocean. The probability density curves have been divided into four categories based upon the mean thickness of the drifting ice: $<1,1-2,2-3$ and $>3 \mathrm{~m}$ (Fig. 8). Mean thickness, as defined here, is the thickness of each sea-ice category in CICE, weighted by their individual concentration. It is therefore a measure of both the mass and compactness of the ice cover. The derived distributions more closely resemble a log-normal distribution in summer than in winter, pointing to extreme values being most prevalent in summer. This is, to our knowledge, the first presentation of a basin-wide direct statistic of the sea-ice inertial oscillation speed for a coupled model.

For the RASMe1 case-study year, inertial oscillation speed and associated deformation are negligible during January-March relative to July-September, even in their extreme values (Fig. 8). They indicate that between winter and summer the pattern shifts toward much stronger oscillations across the central Arctic. Perhaps more importantly, the results from RASM also indicate that the summer shift observed in this case study is not solely attributable to the state of the pack, as demonstrated by the closely clustered curves of each thickness division (Fig. 8). This is evidence that the most significant reason for seasonal differences between summer and winter inertial oscillations is storm activity, rather than factors associated with sea-ice thickness or concentration, as indicated by seasonal differences in surface circulation (Fig. 3). We concede that the RASMe1 realization possesses slightly heightened seasonality in inertial oscillation relative to the buoy record, as indicated by the wavelet analysis (Fig. 6). However, this does not detract from the important point that a change in cyclonic activity, including frequency of occurrence and seasonal shifts, could equally contribute to change in 21 stcentury summer inertial oscillations as could Arctic sea-ice thickness decline. The relationship between climatic changes in sea-ice thickness and storm activity is not easily separated in the complex adaptive Arctic system.

To further demonstrate the seasonal shift in highfrequency drift and divergence magnitude, we analyze spatial distribution of the median inertial oscillation speed for January-March and July-September (Fig. 9), and corresponding root-mean-square (rms) divergence calculated from the clockwise signal (Fig. 10). Note that rms divergence is the most appropriate divergence statistic in this case, since the high-frequency divergence signal oscillates around zero. These have been calculated using methods described in Appendix B and are, to our knowledge, the first direct basinwide statistics of inertial speed and deformation shown for a coupled model. Overlaid on these maps are mean sea-level pressure (Fig. 9) and mean thickness (Fig. 10). Comparing these overlaid statistics between Figures 8 and 10, a thickness bias clearly exists in inertial oscillation and deformation magnitude, but it is also evident that the magnitude of inertial oscillations is influenced by the location of Arctic cyclonic activity. In particular, rms divergence during July-September (Fig. 10) shows strong deformation in ice $<2 \mathrm{~m}$ thick in the Canada Basin, but comparatively quiescent conditions across much of the Amundsen and Nansen basins with ice of similar thickness. A difference between the two regions is that a seasonal depression extends over the areas with greater inertial motion in sea ice, seen in the surface pressure for JulySeptember (Fig. 9).

These results suggest a more subtle connection between sea-ice thickness and inertial oscillations in the pack than may have previously been understood. Cyclones over the ice-ocean boundary layer result in surface divergence in 

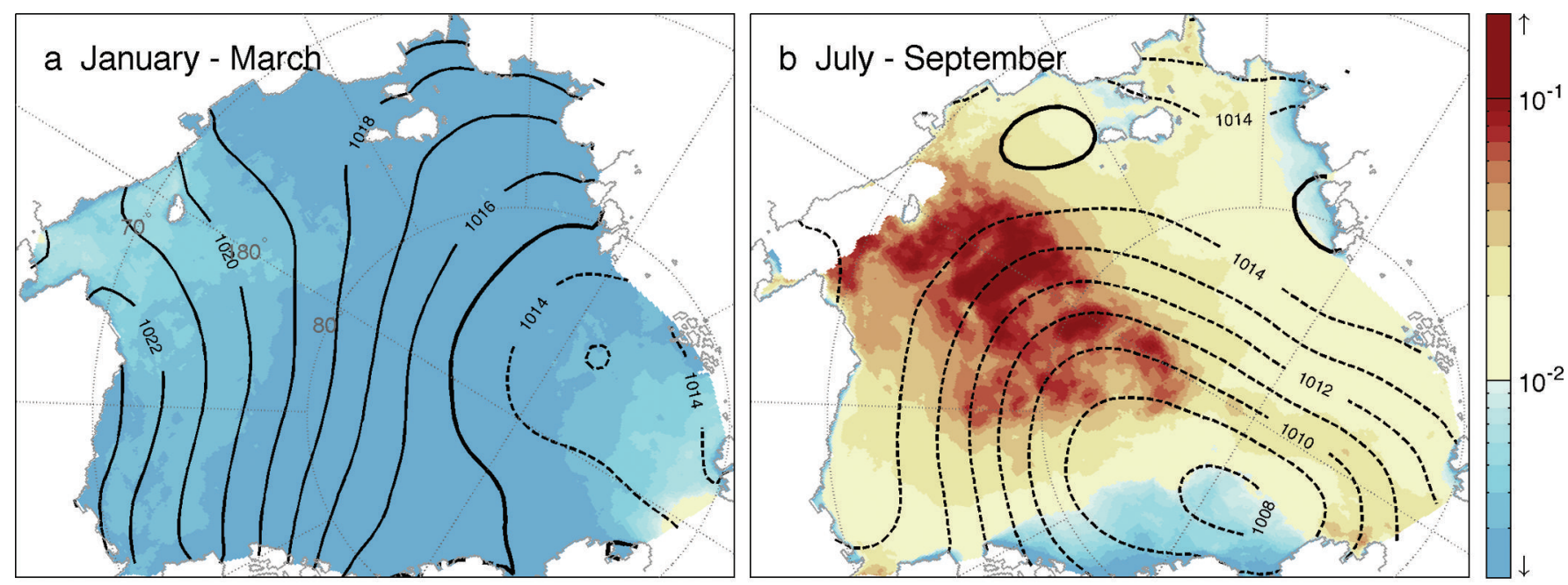

$\mathrm{m} \mathrm{s}^{-1}$

Fig. 9. (a) January-March and (b) July-September 1996 median clockwise $1.8-2.1 \mathrm{~m} \mathrm{~d}^{-1}$ sea-ice drift magnitude. This indicates the inertial speed on a logarithmic color scale for RASMe1 within the central Arctic analysis domain defined in Figure 1. Black contours indicate the corresponding surface air pressure at $1 \mathrm{hPa}$ spacing (solid $>1015 \mathrm{hPa}$; bold $1015 \mathrm{hPa}$; dashed $<1015 \mathrm{hPa}$ ). Areas where the sea-ice concentration is $<15 \%$ at any time in the analysis period are excluded. Corresponding sea-ice thickness and divergence are provided in Figure 10. These spatial medians correspond to the histogram of hourly instantaneous values in Figure 8a.

their wake, and associated Ekman transport and pumping, which is indicated by sea-ice inertial oscillations. These dynamics themselves are associated with near-surface mixing and may result in changes in sea-ice thickness stemming from changes in the oceanic heat flux. Therefore, the strength and prevalence of low-pressure systems traversing the central Arctic in summer needs to be considered when investigating climatic changes in iceocean Ekman transport in the Arctic as part of the same coupled system. This is the reason for the strong seasonal shift in inertial speed and deformation (Fig. 8), irrespective of the mean sea-ice thickness sampled. This is especially relevant in light of recent extreme events, such as the 'Great Arctic Cyclone', which resulted in the 2012 record September minimum sea-ice extent in the satellite era (Simmonds and Rudeva, 2012).

\section{APPLYING RASM COUPLING METHODS IN THE COMMUNITY EARTH SYSTEM MODEL}

To place the RASM case study in context and to demonstrate the consequence of frequent atmosphere-ice-ocean coupling in a global Earth System Model, we have applied the RASM ice-ocean coupling configuration to CESM. The standard version of CESM uses a $30 \mathrm{~min}$ 'fast' coupler time step to exchange fluxes between the atmosphere, land and sea-ice models, and a 'slow' coupler time step to exchange the ocean model daily fluxes with other components via CPL7. In this configuration the ocean model completes twenty-four 1 hour oceanic time steps within each coupler period. A natural consequence of this configuration is that even though the ocean model's internal time step and physics sufficiently resolve Ekman mass transport, the
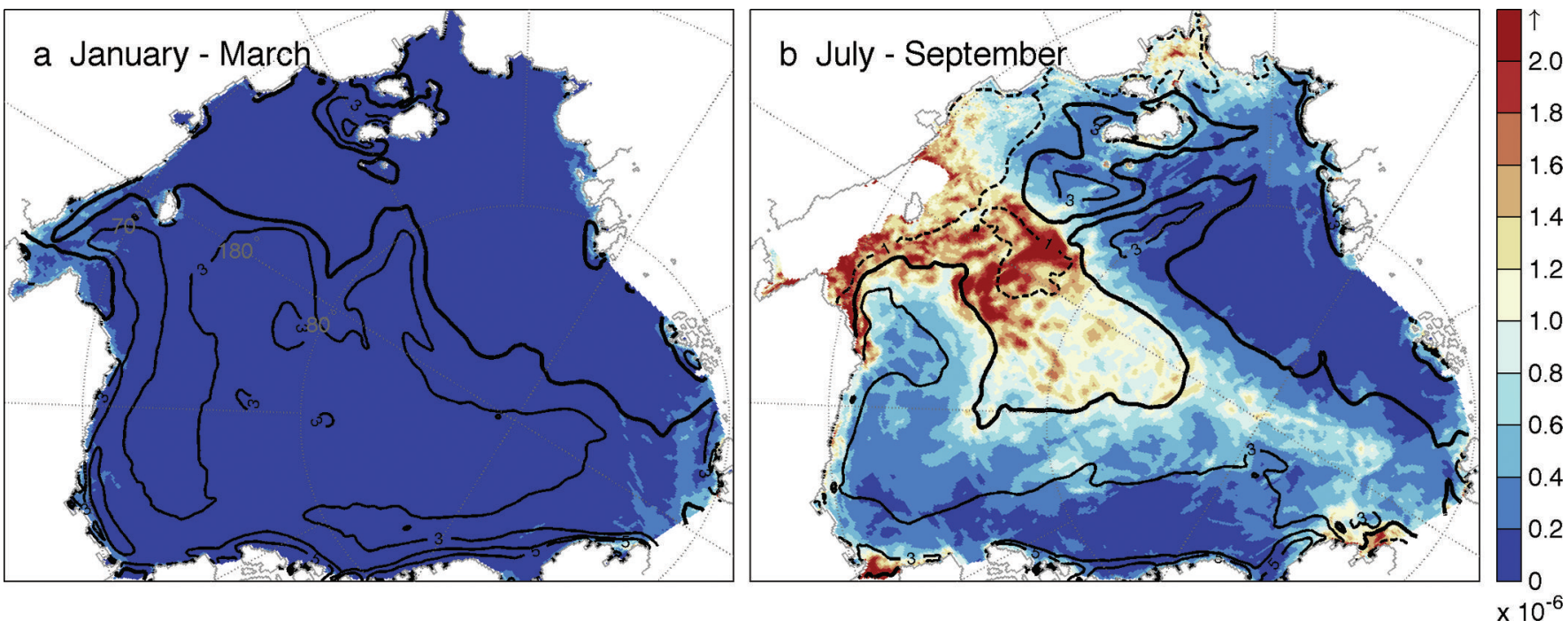

Fig. 10. (a) January-March and (b) July-September 1996 rms divergence $\left(\mathrm{s}^{-1}\right)$ for clockwise $1.8-2.1 \mathrm{~d}^{-1}$ sea-ice drift. Black contours indicate the mean sea-ice thickness at $1 \mathrm{~m}$ spacing (solid $>2 \mathrm{~m}$; bold $2 \mathrm{~m}$; dashed $1 \mathrm{~m}$ ). Areas where the sea-ice concentration is $<15 \%$ at any time in the analysis period are excluded. Corresponding sea-ice inertial speed and surface air pressure are provided in Figure 9 . The rms statistic shown here may be compared with the divergence magnitude histogram in Figure 8b. 

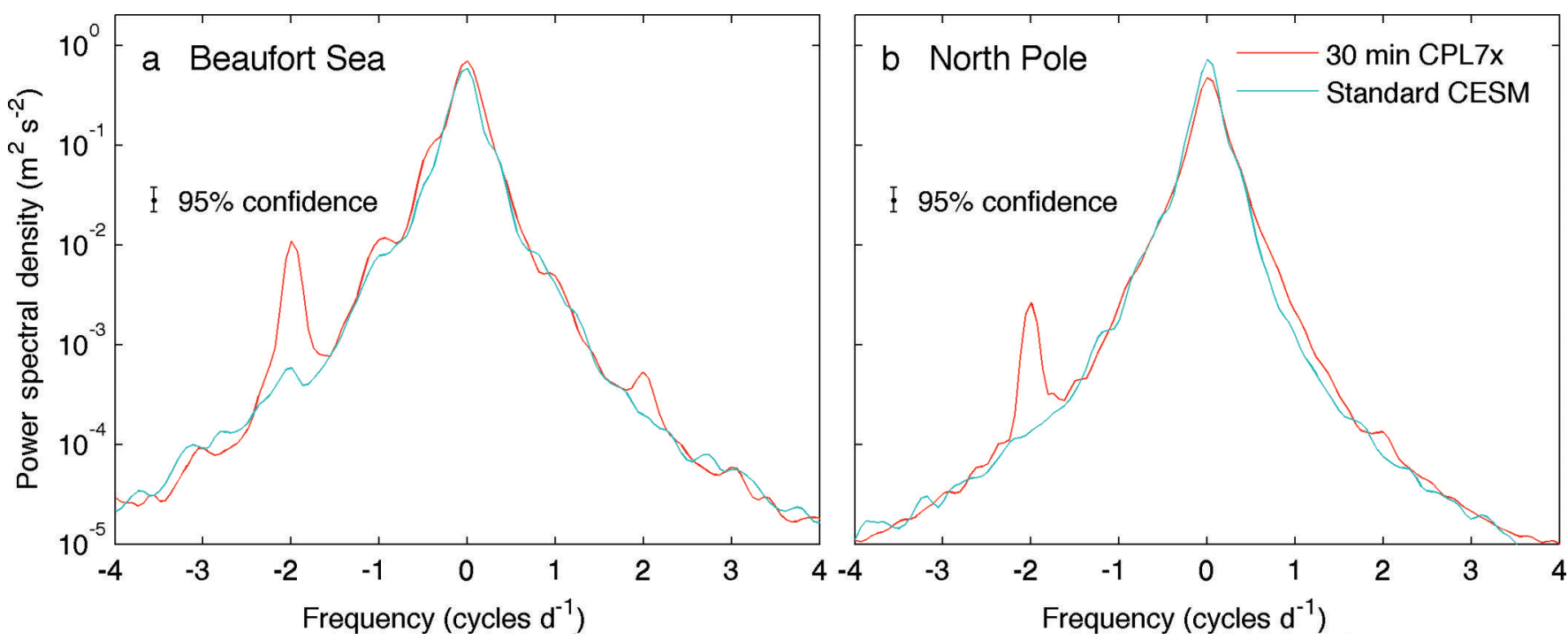

Fig. 11. Rotary power spectral density of sea-ice drift for a 1 year pre-industrial simulation of CESM with (red) and without (blue) highfrequency ocean coupling (CPL7x 30 min ocean coupling and CPL7 daily ocean coupling respectively). The locations of the model gridpoints for which the spectra were calculated in (a) and (b) are indicated in Figure 1.

coupling paradigm does not. In this configuration the Nyquist coupling frequency is $0.5 \mathrm{~d}^{-1}$, which exceeds all inertial frequencies within sea-ice zones. To demonstrate the impact this has on ice-ocean Ekman transport, we completed two CESM integrations, one using CPL7 and another using CPL7x, the latter with the ocean model in the 'fast' 30 min coupling mode. This also required the modification of ocean model time step to allow 17 steps per $30 \mathrm{~min}$ to ensure a non-diffusive ratio of leapfrog to forward time steps in POP. All other aspects of the ocean configuration conform to the public release of CESM Version 1.1, and a summary of the CESM discretization used in this test is provided in Table 2. In this study, the CESM sea-ice model configuration uses the same Brunke and others (2006) variable sea-ice roughness length additions as described for RASM in Appendix A.

A comparison between the two coupling methods was conducted by initializing CESM with pre-industrial initial conditions, spun up over many centuries, then integrating the model forward for one simulated year, with and without the RASM coupling changes. Even though this spawns two different realizations over which climate model comparisons would normally be invalid, the high-frequency nature of the inertial signal allows meaningful comparison between the two short simulations for the physics of interest.

The change in CESM coupling has a substantial impact on the high-frequency component of the ice motion in the Arctic Ocean (Fig. 11). Whereas the standard configuration of CESM possesses little, if any, inertial signal (at $-2 \mathrm{~d}^{-1}$ ) in sea-ice drift (Fig. 11, blue line), the configuration using the CPL7x coupler with 30 min oceanic flux exchange does exhibit the inertial signal (Fig. 11, red line). The significance of this difference is not that a relatively minor long-term drift signal has been added to CESM's sea-ice solution. Rather, the red peaks at $-2 d^{-1}$ (Fig. 11) represent the inclusion of a process previously neglected: ice-ocean Ekman layer dynamics, including transient transport and pumping. This has important implications for oceanic mixing under sea ice during the passage of storms. A minor point to note is that small anticlockwise peaks are also added to the drift signal at $+2 \mathrm{~d}^{-1}$, indicating that internal sea-ice stress is smearing inertial loops into ellipses, as discussed earlier. We suggest that this is an artifact of lower resolution used in CESM, as compared to RASM.

Modifying the coupling in CESM has a large impact on the median inertial sea-ice speed in both the Arctic (Fig. 12) and Antarctic (Fig. 13). These figures were generated by rotary filtering CESM sea-ice velocity at each model gridpoint within $\pm 0.1 \mathrm{~d}^{-1}$ of the local inertial frequency wherever the mean sea-ice concentration exceeded $15 \%$ for each 3 month period shown. In both the Arctic and Antarctic, but particularly the Southern Ocean, improved modeling of ice-ocean Ekman transport can result in an order-of-magnitude increase in the median seasonal magnitude of inertial oscillations across vast tracts of the pack (Figs 12 and 13). Note that the vertical ocean resolution of CESM is considerably less than in RASM, and one may expect an even stronger response in CESM if the number of vertical POP layers is increased close to the surface. The importance of the relative roles of sea-ice strength and storm location, frequency and intensity in determining the magnitude of ice-ocean Ekman transport remains to be

Table 2. Configuration of the Community Earth System Model used in this paper, including changes made to incorporate highfrequency oceanic coupling in italics

\begin{tabular}{|c|c|c|}
\hline Component & Code & Configuration \\
\hline Atmosphere & CAM5 & $\begin{array}{l}1^{\circ}, 31 \text { levels, as described in Neale and others } \\
(2012)\end{array}$ \\
\hline Land & CLM4 & $1^{\circ}$, as described in Lawrence and others (2011) \\
\hline Ocean & POP2 & $\begin{array}{c}1^{\circ}, 60 \text { levels ( } 5 \text { in the top } 50 \mathrm{~m} \text { ), } 24 \text { time steps } \\
\text { per daily flux exchange, changed to } 17 \text { time } \\
\text { steps per } 30 \text { min flux exchange }\end{array}$ \\
\hline Sea ice & CICE4 & $\begin{array}{l}1^{\circ}, 30 \text { min thermodynamics and dynamics time } \\
\text { step, otherwise identical to RASM as described } \\
\text { in this paper. }\end{array}$ \\
\hline Coupler & $\mathrm{CPL} 7$ & $\begin{array}{c}\text { Flux exchange every } 30 \text { min for CAM5, CLM } \\
\text { and CICE, daily for POP2, changed to CPL7x } \\
\text { and } 30 \text { min POP2 coupling }\end{array}$ \\
\hline
\end{tabular}



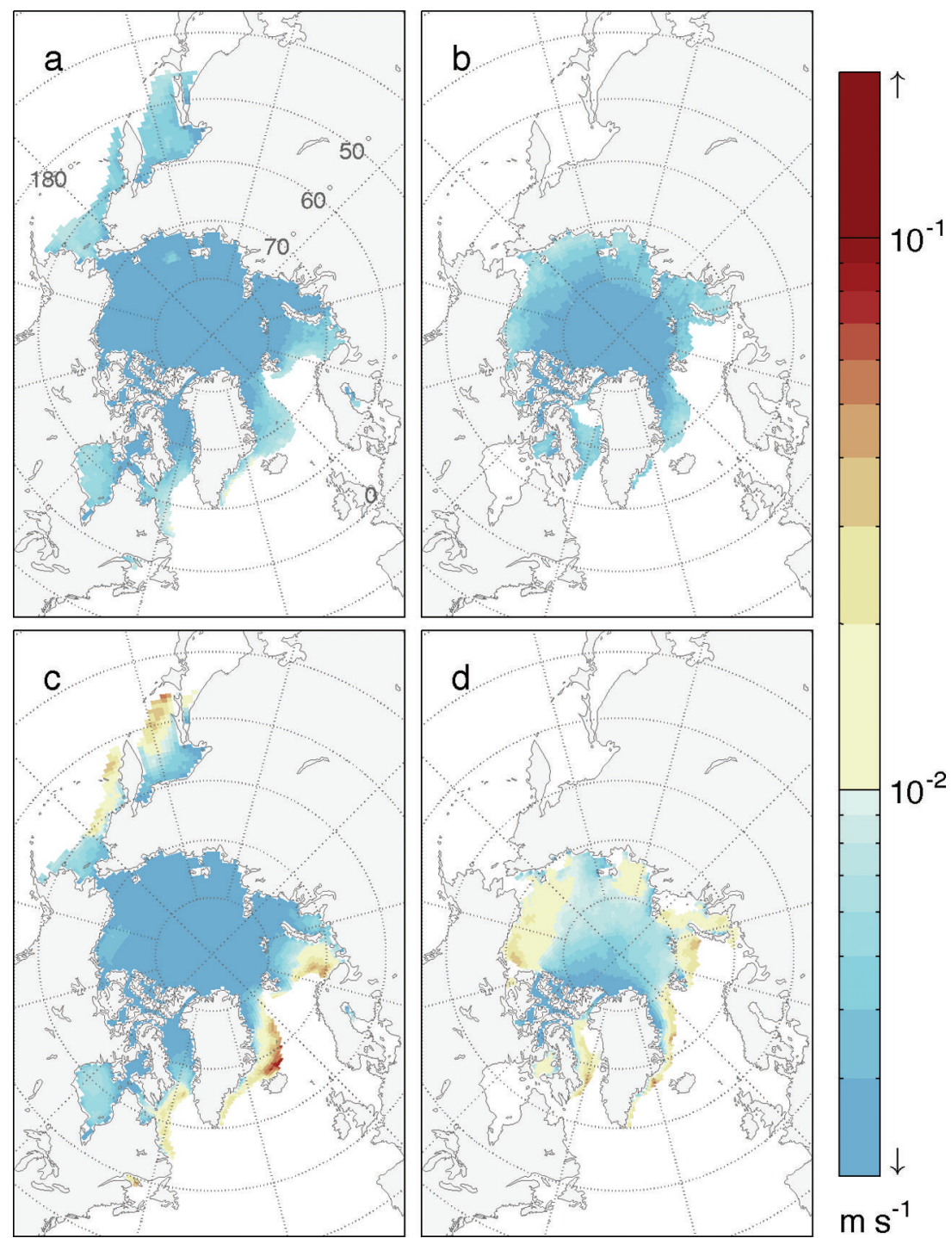

Fig. 12. Arctic median inertial sea-ice speed for a 1 year pre-industrial simulation of CESM without and with high-frequency ocean coupling. (a, b) A standard CESM case with daily ocean coupler steps in combination with $30 \mathrm{~min}$ coupler steps for the atmosphere, land and sea-ice components during (a) January-March and (b) July-September. (c, d) The equivalent values for 30 min coupler steps for all of the atmosphere, land, sea ice and ocean for the same periods: (c) January-March and (d) July-September. The color scale is logarithmic and identical to that in Figure 9.

determined and is a question we intend to pursue using RASM and CESM in a follow-on study.

\section{DISCUSSION}

Perhaps the most important outcome of this investigation is evidence of the significant impact of the coupling time step used in Earth System Models. This point is seldom discussed in the literature, but is important near the poles, where the inertial oscillation period is smallest. By comparing CESM coupling methods with a regionally constrained counterpart (RASM), we have addressed a question that has not been adequately answered in the literature.

Previously it has been suggested that coupled ice-ocean models that do not embed sea ice in the ocean may not adequately simulate inertial oscillations (Hibler and others, 2006). By 'embed sea ice', we mean using an ocean coordinate system that allows Archimedes' principle to apply so that sea ice 'floats' in the ocean model, with the resultant pressure force affecting the ocean's barotropic mode (Hibler and others, 2006). Within the versions of
RASM and CESM used in this study, sea ice is 'levitated', meaning that ice-ocean dynamical coupling is driven purely by their interfacial stresses, and the ocean is not influenced by sea-ice buoyancy. We have demonstrated that this levitated coupling mechanism, while not physically perfect, can model inertial oscillations of similar magnitude to those observed in the pack, as indicated by wavelet coherence. This is not to say that the sea-ice embedding would not improve ice-ocean boundary layer physics. Rather, a $z^{*}$ coordinate system, which is a way of embedding sea ice in the ocean (Campin and others, 2008), is probably more important for improving the barotropic mode for oceanic tides, a component not addressed in this study. Instead, we suggest that a coupling configuration that tightly synchronizes the ice-ocean, atmosphere-ice and atmosphereocean interfacial stress terms is the most important model mechanism required to simulate high-frequency sea-ice mechanics. This addresses our main aims stated in the introduction, and lays open the use of CESM for investigations to understand the climatic influence of storm passage over sea ice in both the Arctic and Southern Ocean. 

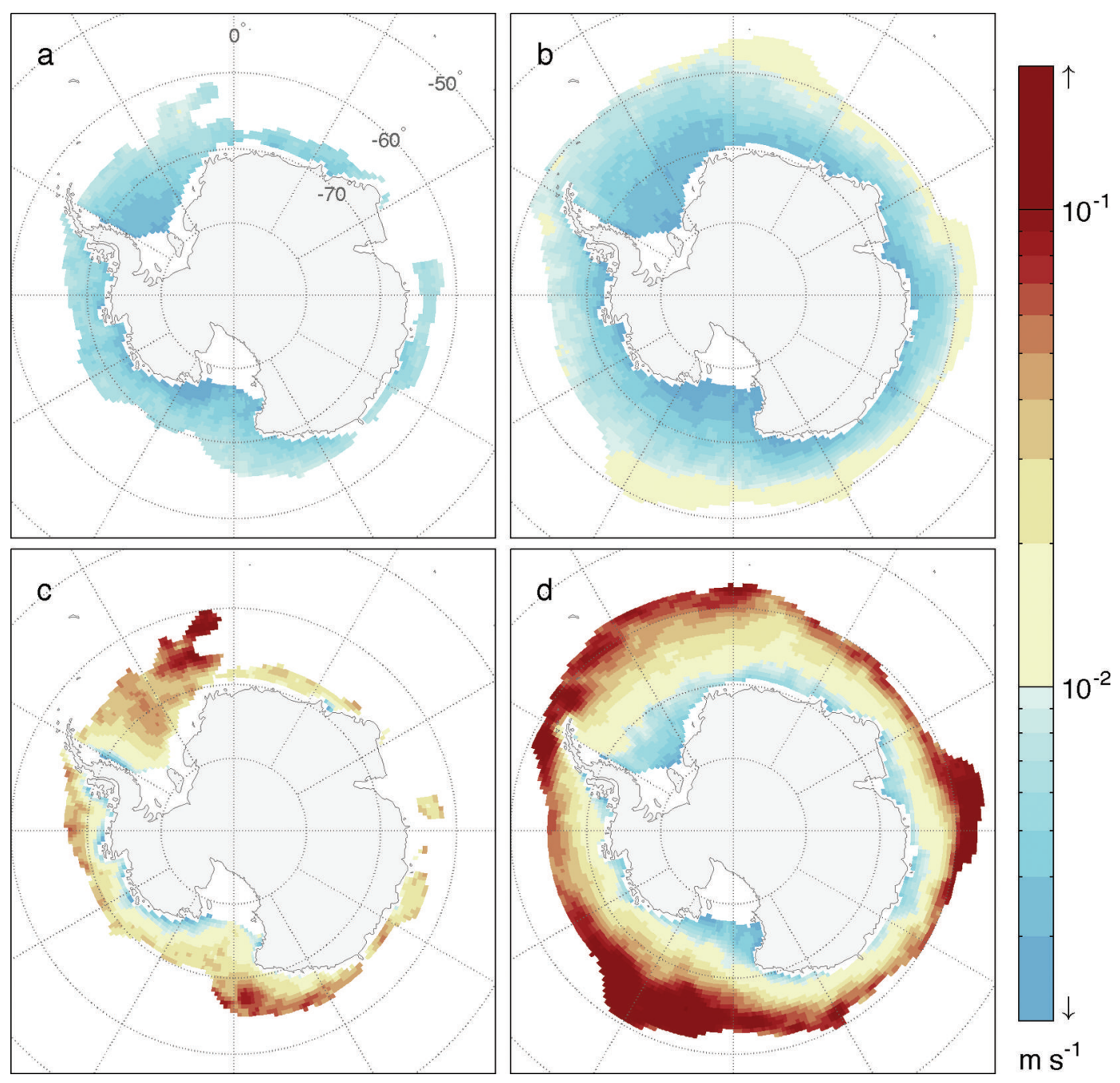

Fig. 13. Same as Figure 12, but for the Antarctic and showing anticlockwise inertial speed.

Both RASM and CESM use five sea-ice thickness categories to approximate sea-ice strength based upon the work of Rothrock (1975). This approach is more sophisticated than the two-category compressive strength approximation of Hibler (1979) used in several present-day global models (IPCC, 2013), and produces a markedly different result in high-resolution models (Maslowski and Lipscomb, 2003). With this in mind, the RASMe1 case study indicates that both the state of the pack and cyclonic activity are important factors that need to be assessed together in understanding inertial motion in sea ice. Therefore it is important that inertial motion is not considered a metric for just thickness and concentration changes, owing to dependence of the strength of Ekman transport on storm activity. For this reason we suggest that it is premature to attribute climatic changes in Arctic inertial oscillations to thickness changes alone. However, there is clear observational evidence that near-inertial waves in the Arctic Ocean are larger and more prevalent in less concentrated sea ice (Fer, 2014; Martini and others, 2014), which corresponds to thinner ice using our mean thickness statistic.

Aside from the particular focus of this research on inertial oscillations, we have demonstrated the utility of a coupled regional model as a tool for model evaluation. We reemphasize that direct comparisons between global coupled models and observations typically require long data records, but for the physics of interest, few buoy records last more than 3 years, often much less, and can be disparately located in the Arctic at any point in time. We have employed a method of constructing the required modeling infrastructure in an Arctic regional model, evaluating it against daily observations in a fully coupled framework, and then applied it to a global coupled model to understand the global significance. In so doing, we have confidence that ice-ocean inertial oscillations and processes associated with them are realistic in CESM when using the coupler improvements engineered in RASM.

\section{CONCLUSION}

The main aim of this work is to demonstrate the impact of the temporal resolution of flux exchanges on integrated iceocean dynamics in Earth System Models. By combining Ekman theory with rotary signal-processing techniques, we have used high-frequency sea-ice velocity as a proxy for the strength of Ekman transport, and thereby of high-frequency ice-ocean dynamics important for the exchange of heat and momentum between polar oceans and the atmosphere. Whereas previous studies on this topic have focused primarily on the impact of ice-ocean Ekman transport on sea-ice drift and deformation, we have framed our investigation in terms of the broader question of whether or not sufficient mixing is being stimulated in the ice-ocean system during the passage of storms. Results in RASM agree with 
previous studies (e.g. Heil and Hibler, 2002) suggesting a significant contribution of high-frequency inertial oscillations to total deformation and thickness change in sea ice (Fig. 7).

By applying a rotary wavelet filter to RASM and CESM sea-ice velocities, we have calculated the hourly inertial speed of three model realizations and provided statistics that address missing physics in some present-day Earth system models related to oceanic mixing in response to passage of storms. By resolving ice-ocean inertia in CESM, there is an order-of-magnitude increase in the median speed of inertial oscillations across large areas of the Southern Ocean pack in winter and summer. The speed increase is more modest in Northern Hemisphere sea ice, but still remains elevated relative to daily oceanic coupling in CESM. This result indicates a need to analyze sea-ice inertial speed, storm tracks and oceanic mixing together in a fully coupled system, in which sea-ice thickness is but one variable subject to coupled feedbacks. To our knowledge, this is the first time the global distribution of rotational-sense sea-ice motion has been calculated and presented in this way for an Earth System Model.

\section{ACKNOWLEDGEMENTS}

This work was supported by the US Department of Energy, the US National Science Foundation (grant No. 1108542) and the Office of Naval Research. Computing resources were provided via a Challenge Grant from the US Department of Defense High Performance Computing Modernization Program. We are grateful for the advice and data supplied by William Hibler III and Petra Heil, and for the suggestions of Xubin Zeng on sea-ice roughness length formulations. Additional observationally based data used in this study were supplied by the US National Snow and Ice Data Center, and the European Center for MediumRange Weather Forecasts. We thank the US National Center for Atmospheric Research for making the CESM code base and pre-industrial initial conditions available for this study. Finally, we thank our two reviewers for helpful comments toward improving this paper.

\section{REFERENCES}

Bi D and 27 others (2013) The ACCESS coupled model: description, control climate and evaluation. Austral. Meterol. Oceanogr. J., 63(1), 41-64

Bitz CM and Lipscomb WH (1999) An energy-conserving thermodynamic model of sea ice. J. Geophys. Res., 104(C7), 15 699-15677 (doi: 10.1029/1999JC900100)

Bitz CM, Holland MM, Weaver AJ and Eby M (2001) Simulating the ice-thickness distribution in a coupled climate model. J. Geophys. Res., 106(C2), 2441-2463

Briegleb BP and Light B (2007) A Delta-Eddington multiple scattering parameterization for solar radiation in the sea ice component of the Community Climate System Model. (NCAR Tech. Note NCAR/TN-472+STR) National Center for Atmospheric Research, Boulder, CO

Bromwich DH, Hines KM and Bai L-S (2009) Development and testing of Polar Weather Research and Forecasting model: 2. Arctic Ocean. J. Geophys. Res., 114(D8), D08122 (doi: 10.1029/2008JD010300)

Brunke MA, Zhou M, Zeng X and Andreas EL (2006) An intercomparison of bulk aerodynamic algorithms used over sea ice with data from the Surface Heat Budget for the Arctic
Ocean (SHEBA) experiment. J. Geophys. Res., 111(C9), C09001 (doi: 10.1029/2005JC002907)

Campbell GS (1974) A simple method for determining unsaturated conductivity from moisture retention data. Soil Sci., 117(6), 311-314

Campin J-M, Marshall J and Ferreira D (2008) Sea ice-ocean coupling using a rescaled vertical coordinate $z^{*}$. Ocean Model., 24(1-2), 1-14 (doi: 10.1016/j.ocemod.2008.05.005)

Chen $C$ and 7 others (2009) A new high-resolution unstructured grid finite volume Arctic Ocean model (AO-FVCOM): an application for tidal studies. J. Geophys. Res., 114(C8), C08017 (doi: 10.1029/2008JC004941)

Collins WD and 7 others (2004) Description of the NCAR Community Atmosphere Model (CAM 3.0). (NCAR Tech. Note NCAR/TN-464+STR) National Center for Atmospheric Research, Boulder, CO

Craig AP, Vertenstein M and Jacob R (2012) A new flexible coupler for earth system modeling developed for CCSM4 and CESM1. Int. J. High Perform. Comput. Appl., 26(1), 31-42 (doi: 10.1177/ 1094342011428141)

Dee DP and 35 others (2011) The ERA-Interim reanalysis: configuration and performance of the data assimilation system. Q. J. R. Meteorol. Soc., 137(656), 553-597 (doi: 10.1002/qj.828)

Dorn W and 6 others (2007) Sensitivities and uncertainties in a coupled regional atmosphere-ocean-ice model with respect to the simulation of Arctic sea ice. J. Geophys. Res., 112(D10), D10118 (doi: 10.1029/2006JD007814)

Dosser HV, Rainville L and Toole JM (2014) Near-inertial internal wave field in the Canada Basin from ice-tethered profilers. J. Phys. Oceanogr., 44(2), 413-426 (doi: 10.1175/JPO-D-13-0117.1)

Dümenil $L$ and Todini E (1992) A rainfall-runoff scheme for use in the Hamburg climate model. In O'Kane JP ed. Advances in theoretical hydrology: a tribute to James Dooge. (European Geophysical Society Series on Hydrological Sciences 1) Elsevier, Amsterdam, 129-157

DuVivier AK and Cassano JJ (2013) Evaluation of WRF model resolution on simulated mesoscale winds and surface fluxes near Greenland. Mon. Weather Rev., 141(3), 941-963 (doi: 10.1175/MWR-D-12-00091.1)

Ek MB and 7 others (2003) Implementation of Noah land surface model advances in the National Centers for Environmental Prediction operational mesoscale Eta model. J. Geophys. Res., 108(D22), 8851 (doi: 10.1029/2002JD003296)

Emery WJ and Thomson RE (2004) Data analysis methods in physical oceanography, 2nd edn. Elsevier, Amsterdam

Fer I (2014) Near-inertial mixing in the central Arctic Ocean. J. Phys. Oceanogr., 44(8), 2031-2049 (doi: 10.1175/JPO-D-13-0133.1)

Geiger CA and Perovich DK (2008) Springtime ice motion in the western Antarctic Peninsula region. Deep-Sea Res. II, 55(3-4), 338-350 (doi: 10.1016/j.dsr2.2007.11.008)

Gent PR and 12 others (2011) The Community Climate System Model Version 4. J. Climate, 24(19), 4973-4991 (doi: 10.1175/ 2011JCLI4083.1)

Gimbert F, Jourdain NC, Weiss J and Barnier B (2012a) Recent mechanical weakening of the Arctic sea ice cover as revealed from larger inertial oscillations. J. Geophys. Res., 117(C11), C00J112 (doi: 10.1029/2011JC007633)

Gimbert F, Marsan D, Weiss J, Jourdain NC and Barnier B (2012b) Sea ice inertial oscillations in the Arctic Basin. Cryosphere, 6(5), 1187-1201 (doi: 10.5194/tc-6-1187-2012)

Griffies SM (2010) Elements of MOM4p1. (GFDL Ocean Group Tech. Rep. 6) National Oceanic and Atmospheric Administration/Geophysical Fluid Dynamics Laboratory, Princeton, NJ

Grinsted A, Moore JC and Jevrejeva S (2004) Application of the cross wavelet transform and wavelet coherence in geophysical time series. Nonlinear Process. Geophys., 11(5-6), 561-566 (doi: 10.5194/npg-11-561-2004)

Guthrie JD, Morison JH and Fer I (2013) Revisiting internal waves and mixing in the Arctic Ocean. J. Geophys. Res., 118(8), 3966-3977 (doi: 10.1002/jgrc.20294) 
Hallberg R (2014) Numerical instabilities of the ice/ocean coupled system. CLIVAR Exch., 65(19/2), 38-42

Heil P and Hibler WD, III (2002) Modeling the high-frequency component of Arctic sea ice drift and deformation. J. Phys. Oceanogr., 32(11), 3039-3057 (doi: 10.1175/1520-0485(2002) 032<3039:MTHFCO>2.0.CO;2)

Hibler WD, III (1979) A dynamic thermodynamic sea ice model. J. Phys. Oceanogr., 9(7), 815-846 (doi: 10.1175/1520-0485 (1979)009<0815:ADTSIM>2.0.CO;2)

Hibler WD, III (1980) Modeling a variable thickness sea ice cover. Mon. Weather Rev., 108(12), 1943-1973 (doi: 10.1175/15200493(1980)108<1943:MAVTSI>2.0.CO;2)

Hibler WD, III, Heil P and Lytle VI (1998) On simulating high frequency variability in Antarctic sea-ice dynamics models. Ann. Glaciol., 27, 443-448

Hibler WD, III, Roberts A, Heil P, Proshutinsky AY, Simmons HL and Lovick J (2006) Modeling M2 tidal variability in Arctic seaice drift and deformation. Ann. Glaciol., 44, 418-428 (doi: 10.3189/172756406781811178)

Hines KM and Bromwich DH (2008) Development and testing of polar weather research and forecasting (WRF) model. Part I: Greenland ice sheet meteorology. Mon. Weather Rev., 136(6), 1971-1989 (doi: 10.1175/2007MWR2112.1)

Holloway G and Proshutinsky A (2007) Role of tides in Arctic ocean/ice climate. J. Geophys. Res., 112(C4), C04S06 (doi: 10.1029/2006JC003643)

Hormazabal S, Shaffer G and Leth O (2004) Coastal transition zone off Chile. J. Geophys. Res., 109(C1), C01021 (doi: 10.1029/ 2003JC001956)

Hunke EC and Dukowicz JK (1997) An elastic-viscous-plastic model for sea ice dynamics. J. Phys. Oceanogr., 27(9), 1849-1867 (doi: 10.1175/1520-0485(1997)027<1849:AEVPMF>2.0.CO;2)

Hunke EC and Lipscomb WH (2010) CICE: the Los Alamos sea ice model documentation and software user's manual, Version 4.1. (Tech. Rep. LA-CC-06-012) Los Alamos National Laboratory, Los Alamos, NM

Hunkins K (1967) Inertial oscillations of Fletcher's Ice Island (T-3). J. Geophys. Res., 72(4), 1165-1174 (doi: 10.1029/ JZ072i004p01165)

Hurrell JW and 22 others (2013) The Community Earth System Model: a framework for collaborative research. Bull. Am. Meteorol. Soc., 94(9), 1339-1360 (doi: 10.1175/BAMS-D-1200121.1)

Karvonen J (2014) A sea ice concentration estimation algorithm utilizing radiometer and SAR data. Cryosphere, 8(5), 1639-1650 (doi: 10.5194/tc-8-1639-2014)

Kowalik Z and Proshutinsky AY (1994) The Arctic Ocean tides. In Johannessen OM, Muench RD and Overland JE eds The polar oceans and their role in shaping the global environment: the Nansen Centennial volume. (Geophysical Monograph 85) American Geophysical Union, Washington, DC, 137-158

Kwok R, Cunningham GF and Hibler WD, III (2003) Sub-daily sea ice motion and deformation from RADARSAT observations. Geophys. Res. Lett., 30(23), 2218 (doi: 10.1029/2003GL018723)

Lammert A, Brummer B and Kaleschke L (2009) Observation of cyclone-induced inertial sea-ice oscillation in Fram Strait. Geophys. Res. Lett., 36(10), L10503 (doi: 10.1029/2009GL037197)

Large WG and Yeager SG (2008) The global climatology of an interannually varying air-sea flux data set. Climate Dyn., 33(2-3), 341-364 (doi: 10.1007/s00382-008-0441-3)

Large WG, Williams JC and Doney SC (1994) Oceanic vertical mixing: a review and a model with a nonlocal boundary layer parameterization. Rev. Geophys., 32(4), 397-422 (doi: 10.1029/ 94RG01872)

Lawrence D and 11 others (2011) Parameterization improvements and functional and structural advances in version 4 of the Community Land Model. J. Adv. Model. Earth Syst., 3(M3), M03001 (doi: 10.1029/2011MS000045)

Leppäranta M, Oikkonen A, Shirasawa K and Fukamachi Y (2012) A treatise on frequency spectrum of drift ice velocity. Cold Reg.
Sci. Technol., 76-77, 83-91 (doi: 10.1016/j.coldregions. 2011.12.005)

Liang X, Lettenmaier DP, Wood EF and Burges SJ (1994) A simple hydrologically based model of land surface water and energy fluxes for general circulation models. J. Geophys. Res., 99(D7), 14 415-14 428 (doi: 10.1029/94JD00483)

Lipscomb WH (2001) Remapping the thickness distribution in sea ice models. J. Geophys. Res., 106(C7), 13989-14000 (doi: 10.1029/2000JC000518)

Lipscomb WH and Hunke EC (2004) Modeling sea ice transport using incremental remapping. Mon. Weather Rev., 132(6), 1341-1354 (doi: 10.1175/1520-0493(2004)132<1341: MSITUI>2.0.CO;2)

Lipscomb WH, Hunke EC, Maslowski W and Jakacki J (2007) Ridging, strength, and stability in high-resolution sea ice models. J. Geophys. Res., 112(C3), C03S91 (doi: 10.1029/ 2005JC003355)

Liu PC and Miller GS (1996) Wavelet transforms and ocean current data analysis. J. Atmos. Oceanic Technol., 13(5), 1090-1099 (doi: 10.1175/1520-0426(1996)013<1090:WTAOCD>2.0.CO;2)

Maraun D and Kurths J (2004) Cross wavelet analysis: significance testing and pitfalls. Nonlinear Process. Geophys., 11(4), 505-514 (doi: 10.5194/npg-11-505-2004)

Martini KI, Simmons HL, Stoudt CA and Hutchings JK (2014) Near-inertial internal waves and sea ice in the Beaufort Sea. J. Phys. Oceanogr., 44(8), 2212-2234 (doi: 10.1175/JPO-D-130160.1)

Maslowski W and Lipscomb WH (2003) High resolution simulations of Arctic sea ice, 1979-1993. Polar Res., 22(1), 67-74 (doi: 10.1111/j.1751-8369.2003.tb00097.x)

Maslowski W, Clement Kinney JL, Marble DC and Jakacki J (2008) Towards eddy-resolving models of the Arctic Ocean. In Hecht MW and Hasumi H eds. Ocean modeling in an eddying regime. American Geophysical Union, Washington, DC

Maslowski W, Clement Kinney J, Higgins M and Roberts A (2012) The future of Arctic sea ice. Annu. Rev. Earth Planet. Sci., 40, 625-654 (doi: 10.1146/annurev-earth-042711-105345)

McPhee MG (1978) A simulation of inertial oscillation in drifting pack ice. Dyn. Atmos. Oceans, 2(2), 107-122 (doi: 10.1016/ 0377-0265(78)90005-2)

McPhee MG (1988) Analysis and prediction of short-term ice drift. J. Offshore Mech. Arct. Eng. ASME, 110(1), 94-100 (doi: 10.1115/1.3257130)

McPhee M (2008) Air-ice-ocean interaction: turbulent ocean boundary layer exchange processes. Springer, New York

Meier W (2013) Climate Data Record Program (CDR): climate algorithm theoretical basis document (C-ATBD), passive microwave sea ice concentration. (CDR Document No. CDRP-ATBD0107) National Oceanic and Atmospheric Administration, Washington, DC http://nsidc.org/data/docs/noaa/g02202_ice_ conc_cdr/pdf/Sealce_CDR_CATBD_final.pdf

Mirollo RE and Strogatz SH (2005) The spectrum of the locked state for the Kuramoto model of coupled oscillators. Physica $D$, 205(1-4), 249-266 (doi: 10.1016/j.physd.2005.01.017)

Morrison H, Thompson G and Tatarskii V (2009) Impact of cloud microphysics on the development of trailing stratiform precipitation in a simulated squall line: comparison of one- and twomoment schemes. Mon. Weather Rev., 137(3), 991-1007 (doi: 10.1175/2008MWR2556.1)

Neale RB and 23 others (2012) Description of the NCAR Community Atmosphere Model (CAM 5.0). (NCAR Tech. Note NCAR/TN-486+STR) National Center for Atmospheric Research, Boulder, $\mathrm{CO}$

Park JJ, Kim K and King BA (2005) Global statistics of inertial motions. Geophys. Res. Lett., 32(14), L14612 (doi: 10.1029/ 2005GL023258)

Park JJ, Kim K and Schmitt RW (2009) Global distribution of the decay timescale of mixed layer inertial motions observed by satellite-tracked drifters. J. Geophys. Res., 114(C11), C11010 (doi: 10.1029/2008JC005216) 
Pnyushkov AV and Polyakov IV (2012) Observations of tidally induced currents over the continental slope of the Laptev Sea, Arctic Ocean. J. Phys. Oceanogr., 42(1), 8-94 (doi: 10.1175/ JPO-D-11-064.1)

Priestley MB (1981) Spectral analysis and time series. Academic Press, London

Rainville L and Woodgate RA (2009) Observations of internal wave generation in the seasonally ice-free Arctic. Geophys. Res. Lett., 36(23), L23604 (doi: 10.1029/2009GL041291)

Rath W, Greatbatch RJ and Zhai X (2014) On the spatial and temporal distribution of near-inertial energy in the Southern Ocean. J. Geophys. Res., 119(1), 359-376 (doi: 10.1002/ 2013JC009246)

Roberts A and 7 others (2010) A science plan for regional Arctic system modeling: a report by the Arctic Research Community for the National Science Foundation Office of Polar Programs. (Tech. Pap. 10-0001) International Arctic Research Center, University of Alaska Fairbanks, Fairbanks, AK http://www.iarc.uaf.edu/sites/ default/files/publications/reports/IARCTP10-0001.pdf

Rothrock DA (1975) The energetics of the plastic deformation of pack ice by ridging. J. Geophys. Res., 80(33), 4514-4519 (doi: 10.1029/JC080i033p04514)

Simmonds I and Rudeva I (2012) The great Arctic cyclone of August 2012. Geophys. Res. Lett., 39(23), L23709 (doi: 10.1029/ 2012GL054259)

Skamarock W and 7 others (2008) A description of the Advanced Research WRF Version 3. (NCAR Tech. Note NCAR/TN-475 +STR) University Corporation for Atmospheric Research (UCAR)/National Center for Atmospheric Research (NCAR)/ UCAR Community Programs (UCP), Boulder, CO (doi: 10.5065/ D68S4MVH)

Smith R and 19 others (2010) The Parallel Ocean Program (POP) reference manual: ocean component of the Community Climate System Model (CCSM) and Community Earth System Model (CESM). (Tech. Rep. LAUR-10-01853) Los Alamos National Laboratory, Los Alamos, NM http://www.cesm.ucar.edu/models/cesm1.0/pop2/doc/sci/POPRefManual.pdf

Steele M, Morley R and Ermold W (2001) PHC: a global ocean hydrography with a high-quality Arctic Ocean. J. Climate, 14(9), 2079-2087 (doi: 10.1175/1520-0442(2001)014<2079: PAGOHW $>2.0 . \mathrm{CO} ; 2)$

Stocker TF and 9 others eds (2013) Climate change 2013: the physical science basis. Contribution of Working Group I to the Fifth Assessment Report of the Intergovernmental Panel on Climate Change. Cambridge University Press, Cambridge and New York

Thorndike AS, Rothrock DA, Maykut GA and Colony R (1975) The thickness distribution of sea ice. J. Geophys. Res., 80(33), 4501-4513 (doi: 10.1029/JC080i033p04501)

Todini E (1996) The ARNO rainfall-runoff model. J. Hydrol., 175(1-4), 339-382 (doi: 10.1016/S0022-1694(96)80016-3)

Torrence C and Compo GP (1998) A practical guide to wavelet analysis. Bull. Am. Meteorol. Soc., 79(1), 61-78 (doi: 10.1175/ 1520-0477(1998)079<0061:APGTWA $>2.0 . C O ; 2)$

Zhao R-J, Zuang Y-L, Fang L-R, Liu X-R and Zhang Q-S (1980) The Xinanjiang model. IAHS Publ. 129 (Symposium at Oxford 1980 - Hydrological Forecasting), 351-356

\section{APPENDIX A: TECHNICAL DETAILS OF MODELS WITHIN THE REGIONAL ARCTIC SYSTEM MODEL}

This appendix provides a technical description of individual models that make up the Regional Arctic System Model. For the ocean, POP is coupled to the other components in RASM in the same manner as in CESM (Smith and others, 2010), except for regional constraints and coupling synchronization. Oceanic state at the edge of the model domain is supplied via Newtonian relaxation of 71 gridpoints adjacent to the closed lateral boundaries across all vertical levels. The relaxation strength is 30 days for the first 48 gridpoints inward from the boundary, and linearly weakens to zero at 71 gridpoints in from the lateral edge. We have used the monthly PHC temperature and salinity climatology interpolated to model time steps as the boundary condition (Steele and others, 2001). This is sufficient for investigating decadal timescales for which RASM is designed, and where the primary signal of interest derives from atmospheric coupling. We use a second-order-accurate leapfrog scheme with time steps of $\sim 2$ min plus one averaging time step within each 20 min coupling period to limit numerical diffusivity.

Within RASM, POP has 45 vertical ocean layers, with 7 ocean layers in the upper $42 \mathrm{~m}$ to carefully resolve Ekman layer dynamics. POP's Richardson-number dependent mixing scheme is used with a background diffusivity and viscosity of $5 \times 10^{-6} \mathrm{~m}^{2} \mathrm{~s}^{-1}$ and $2 \times 10^{-5} \mathrm{~m}^{2} \mathrm{~s}^{-1}$, respectively, and a mixing coefficient of $0.005 \mathrm{~m}^{2} \mathrm{~s}^{-1}$. This is different from the K-profile parameterization (Large and others, 1994) used in CESM simulations presented in this paper. Important to this study is that the ice-ocean quadratic interfacial stress $\widetilde{\tau}_{w}=\rho_{0} C_{0}\left|\widetilde{u}_{0}(0)-\widetilde{u}_{i}\right|\left(\widetilde{u}_{0}(0)-\widetilde{u}_{i}\right)$ is calculated in CICE using the surface current $\widetilde{u}_{0}(0)$ communicated via the coupler using a neutrally buoyant drag coefficient $C_{o}=$ 0.00536 for a given sea-ice drift $\widetilde{u}_{\mathrm{i}}$.

The sea-ice model used in this study is CICE version 4, as described in Hunke and Lipscomb (2010). It is coupled to other models in RASM in an identical way to CESM, except for changes described here. We use the vertical sea-ice thermodynamic model of Bitz and Lipscomb (1999), the elastic-viscous-plastic approximation (Hunke and Dukowicz, 1997), incremental remapping for advection (Lipscomb and Hunke, 2004) and remapping between ice thickness categories for vertical growth, deformation and melt following Lipscomb (2001). Surface shortwave albedo is calculated using the Delta-Eddington scheme for two bands partitioned at $700 \mathrm{~nm}$ (Briegleb and Light, 2007), and used by the CAM radiation scheme in WRF to calculate dual-band net downward surface shortwave radiation. We use four vertical sea-ice layers and one snow layer for each of the five ice thickness categories divided as listed in Table 1, with 2 min dynamic time steps to tightly converge the elliptic yield curve within each 20 min thermodynamic time step, set to be the same as the coupling period.

The most important change to the cited version of CICE as used in this study is to the flux parameterization for surface wind stress, sensible and latent heat fluxes, respectively:

$$
\begin{aligned}
\widetilde{\tau}_{\mathrm{a}} & =\rho_{\mathrm{a}} C_{\mathrm{d}} \max \left(\mathrm{u}_{\min },\left|\widetilde{u}_{\mathrm{a}}-\widetilde{u}_{\mathrm{i}}\right|\right)\left(\widetilde{u}_{\mathrm{a}}-\widetilde{u}_{\mathrm{i}}\right) \\
F_{\mathrm{s}} & =\rho_{\mathrm{a}} C_{\mathrm{s}} \max \left(\mathrm{u}_{\min },\left|\widetilde{u}_{\mathrm{a}}-\widetilde{u}_{\mathrm{i}}\right|\right)\left(\theta_{\mathrm{a}}-T_{\mathrm{s}}\right) \\
F_{\mathrm{I}} & =\rho_{\mathrm{a}} C_{\mathrm{I}} \max \left(\mathrm{u}_{\min ,},\left|\widetilde{u}_{\mathrm{a}}-\widetilde{u}_{\mathrm{i}}\right|\right)\left(Q_{\mathrm{a}}-Q_{\mathrm{s}}\right)
\end{aligned}
$$

where the drag coefficient $C_{\mathrm{d}}$, and transfer coefficients $C_{\mathrm{s}}$ and $C_{1}$ are dependent upon $\max \left(u_{\text {crit, }},\left|\widetilde{u}_{a}-\widetilde{u}_{i}\right|\right)$ for wind velocity $\widetilde{u}_{\mathrm{a}}$ and air density $\rho_{\mathrm{a}}$ at a reference level $10 \mathrm{~m}$ above the surface. $\theta_{\mathrm{a}}$ and $Q_{\mathrm{a}}$ are the corresponding potential air temperature and specific humidity, given the respective surface temperature $T_{\mathrm{s}}$ and specific humidity $Q_{\mathrm{s}}$. In lowerresolution CESM simulations it has been assumed that $u_{\text {crit }}=u_{\min }=1 \mathrm{~m} \mathrm{~s}^{-1}$ and $\left|\widetilde{u}_{\mathrm{i}}\right|=0$ for the purpose of iceatmosphere flux coupling. However, for coupled mesoscale atmospheric simulations with potential for locally more extreme surface winds and ice speeds, it is physically more realistic not to make this assumption. However, when $\left|\widetilde{u}_{i}\right| \geq 0$ is allowed, small background turbulent flux errors 
and a momentum leak occur when using the above flux equations, leading, among other things, to misdirection in ice-ocean mass transport. This can be seen when $\left|\widetilde{u}_{\mathrm{a}}\right|=0$ and $\left|\widetilde{u}_{i}\right|>0$. The leak is avoided by setting $u_{\min }=0$, while still maintaining $u_{\text {crit }}=1 \mathrm{~m} \mathrm{~s}^{-1}$ to avoid singularities in atmospheric stability parameter calculations described in Hunke and Lipscomb (2010). An important benefit of this approach is that it accommodates the Brunke and others (2006) variable roughness length parameterization for sea ice, which we have implemented in RASM. In this parameterization, roughness lengths $\left(z_{0}\right)$ differ most from the default CICE flux scheme for low frictional velocity values in the critical range $0 \leq\left|\widetilde{u}_{\mathrm{a}}-\widetilde{u}_{\mathrm{i}}\right|<1 \mathrm{~ms}^{-1}$, and in RASM are calculated based on stability over the thickest sea-ice category with nonzero ice volume. A result of these changes is that sea-ice free drift exhibits spin-down characteristics in RASM for $\left|\widetilde{u}_{\mathrm{a}}\right|=0$ that are consistent with theory. An analogous change has been made to CPL7x for atmosphere-ocean coupling which uses the same Monin-Obukhov algorithm, substituting $\widetilde{u}_{\mathrm{o}}(0)$ in place of $\widetilde{u}_{\mathrm{i}}$, but without consequence for the Brunke and others (2006) scheme.

WRF represents the atmosphere in RASM, and has undergone considerable development within RASM for coupled climate modeling as compared to the stand-alone version documented in Skamarock and others (2008). WRF in RASM uses $2.5 \mathrm{~min}$ time steps, is coupled every $20 \mathrm{~min}$, and has 40 vertical levels with finest column resolution focused on the planetary boundary layer to improve cryospheric coupling. The lowest sigma level sits at $\sim 12 \mathrm{~m}$ above sea ice, with typically ten vertical levels within the lowest $1000 \mathrm{~m}$ over the sea ice and ocean. Surface fluxes and surface roughness length $\left(z_{0}\right)$ are determined within the seaice and land models and, for the ocean, within CPL7x. These fluxes and $\log \left(z_{0}\right)$ are passed to WRF via CPL7x, whereby surface stability is determined by inverting the surface fluxes using $z_{0}$ and the standard boundary layer parameterizations from stand-alone WRF. Parametric boundary conditions for sea ice, as used in Polar WRF (Hines and Bromwich, 2008; Bromwich and others, 2009), are neither used nor needed in RASM because it is a fully coupled model. The WRF implementation of the CAM radiation scheme (Collins and others, 2004) is used here with a 20 min time step. It has been changed from the standard WRF code to use surface albedo calculated within the CICE, VIC and, for the ocean, within CPL7x, so as to replicate the original method used within CESM. Our CAM radiation scheme implementation also includes coupling of the liquid and ice droplet sizes with the Morrison microphysics (Morrison and others, 2009), which we have found to be important for the surface radiation balance over sea ice. In this study, a droplet concentration of $8 \times 10^{7} \mathrm{~m}^{-3}$ is used in the microphysics scheme.

In RASM, the VIC land model (Liang and others, 1994, and updates thereupon) has significant modifications from its stand-alone version, and replaces the Noah land surface scheme (Ek and others, 2003) typically used in stand-alone WRF. VIC represents subgrid variability in soil water storage capacity as a spatial probability distribution related to surface runoff (Zhao and others, 1980). It parameterizes base flow through a lower soil moisture zone as a nonlinear recession (Dümenil and Todini, 1992; Todini, 1996). Movement of moisture between the three soil layers is modeled as gravity drainage, with the unsaturated hydraulic conductivity a function of the degree of soil saturation (Campbell, 1974). Surface and subsurface flows generated at the gridcell level are assumed to reach a channel within each gridcell. The routing model that delivers these flows to the ocean model is not included in the model version in this work. However, these flows do not materially affect the short-duration simulation and high-frequency physics of interest in this particular paper. Within RASM, VIC uses a 20 min model time step.

\section{APPENDIX B: ROTARY ANALYSIS AND FILTERING OF SEA-ICE DRIFT, DEFORMATION AND THICKNESS}

Details of the signal analysis conducted in this paper are provided here to ensure reproducibility. References are included to which the reader can refer for further explanation. To compare modeled and observed sea-ice drift in frequency space, clockwise and anticlockwise drift signals are separated using rotary signal analysis for the complex time series $\widetilde{u}_{\mathrm{i}}(t)=u_{\mathrm{i}}(t)+i v_{\mathrm{i}}(t)$ given orthogonal sea-ice drift components $u_{\mathrm{i}}$ and $v_{\mathrm{i}}$. Two-sided power spectral density (PSD) is constructed using the covariance method described in Priestley (1981) from hourly model output, and buoy time series are synchronized to this output with linear interpolation. We use an effective bandwidth of $0.0623 \mathrm{~d}^{-1}$ to calculate biased autocovariance with a maximum lag of 8 days and data length $M=192$ from hourly samples, upon which the PSD is calculated using a Parzen window of size $2 M+1$. A $95 \%$ confidence interval is then calculated for the spectral power following, for example, Emery and Thomson (2004), resulting in confidence limits provided for Figures 5 and 11.

More precise information about the high-frequency drift signal is obtained using the rotary wavelet filter as described in an appendix of Hormazabal and other (2004). However, in this work we have used an 18th-order derivative-ofGaussian (DOG) wavelet. This is used to extract clockwise signals at $1.8-2.1 \mathrm{~d}^{-1}$ in RASM, which are then used to construct Figures $8-10$. It is also used to filter the inertial frequency $\pm 0.1 \mathrm{~d}^{-1}$ for CESM maps in Figures 12 and 13. This is a way of isolating the Ekman component of modeled sea-ice drift, $\widetilde{u}_{i e}$, from the geostrophic component, $\widetilde{u}_{\text {ig. }}$. It also helps in separating the M2 and S2 tidal components from $\widetilde{u}_{i e}$, for which the dominant rotation is in the opposite direction from the inertial component at the locations of IABP 9364 and 9365 in the Arctic basin. Sea-ice deformation can be calculated using the filtered clockwise and anticlockwise velocity, which was done to derive inertial sea-ice deformation statistics in Figures 8 and 10.

Tests not shown in this paper reveal that the 18th-order DOG rotary wavelet filter reconstructs the entire original signal of a filtered time series with $<1 \%$ rms error and $\sim 99.99 \%$ variance retention. The technique is analogous to complex demodulation (e.g. McPhee, 1988; Dosser and others, 2014), but has the advantage that it can be applied across a broad range of frequencies, rather than to a single Fourier band. This facilitates efficient domain-wide analysis of transient inertial oscillation magnitudes, where the resonant frequency varies significantly between the North Pole and Bering Strait, for example, and avoids the need for Fourier-based proxies, such as the 'M-parameter' used in Gimbert and others (2012b). The technique is better suited to high-frequency non-stationary ice-ocean processes.

We also apply the same high-order wavelet to obtain the rotary wavelet power of each complex time series $\widetilde{u}_{\mathrm{i}}(t)$, 
extending the scalar analysis of Grinsted and others (2004) to vector analysis. This is used to construct the wavelet diagrams in Figure 6. For all wavelet processing, we employ a fine binary logarithmic scale with resolution $\delta j=0.025$ as discussed in Torrence and Compo (1998). We especially refer the reader to the particular details of how wavelet coherence squared $\left(R^{2}\right)$ is calculated, which is carefully described in Grinsted and others (2004). In brief, wavelet coherence squared is an extension of spectral cross coherence squared, as described in Priestley (1981) and also Emery and Thomson (2004). Cross coherence squared is the ratio of the square of cross spectral power over the product of the square of each power of the two individual signals being compared, calculated for each Fourier frequency band. Due to the squared quantities involved, it is an exacting metric of the relative power and periodicity of two signals because if either of these slightly disagree the associated cross coherence squared is poor. The same fundamental meaning applies to wavelet coherence squared, but for individual periods and points in time (Maraun and Kurths, 2004). However, the calculation of wavelet coherence squared is slightly more complicated due to the additional information required for scale and smoothing to complete the calculation, as given in equation 8 of Grinsted and others (2004).

Finally, high-frequency thickness and total deformation changes presented in Figure 7 are extracted using a 96thorder zero-phase finite impulse response filter with a Hamming window, a pass-band ripple not exceeding $0.09 \mathrm{~dB}$ and stop-band attenuation of $-30 \mathrm{~dB}$ or less. 